\title{
Effects of R134a Saturation Temperature on a Shell and Tube Condenser with the Nanofluid Flow in the Tube Using the Thermal Efficiency and Effectiveness Concepts
}

\author{
Élcio Nogueira \\ Department of Mechanics and Energy, State University of Rio de Janeiro, DEM/FAT/UERJ, Resende, Brazil \\ Email: elcionogueira@hotmail.com
}

How to cite this paper: Nogueira, É. (2021) Effects of R134a Saturation Temperature on a Shell and Tube Condenser with the Nanofluid Flow in the Tube Using the Thermal Efficiency and Effectiveness Concepts. World Journal of Nano Science and Engineering, 11, 1-24.

https://doi.org/10.4236/wjnse.2021.111001

Received: February 9, 2021

Accepted: March 22, 2021

Published: March 25, 2021

Copyright $\odot 2021$ by author(s) and Scientific Research Publishing Inc. This work is licensed under the Creative Commons Attribution International License (CC BY 4.0).

http://creativecommons.org/licenses/by/4.0/

\begin{abstract}
The work's objective is to analyze the influence of the saturation temperature of the R134a refrigerant on the thermal performance of a shell and tube type condenser, with water and aluminum oxide $\left(\mathrm{Al}_{2} \mathrm{O}_{3}\right)$ nanoparticles flowing into the tube. For analysis, the heat exchanger is subdivided into three regions: subcooled liquid, saturated steam, and superheated steam. The shell and tube heat exchanger assumed as the basis for the study has 36 tubes, with rows of 4 tubes in line and three passes into the tube in each region. The parameters used to analyze the performance are efficiency and effectiveness, through variations of quantities such as saturation temperature, the nanofluid's mass flow rate, fraction in the nanoparticles' volume, and the number of passes in the tube in each region of the heat exchanger. The obtained results demonstrate that the efficiency is relatively high in all the analyzed situations. In each saturation temperature, the effectiveness can be increased by introducing fractions of nanoparticles in the water or increasing the number of passes in the tube.
\end{abstract}

\section{Keywords}

Shell and Tube Condenser, R134a, Nanofluid, Thermal Efficiency, Thermal Effectiveness

\section{Introduction}

Two relevant aspects must be highlighted in this work about the use of heat ex- 
changers:

1) The use of nanoparticles to increase effectiveness, that is, to increase the heat exchange as a function of the total available heat;

2) The use of efficiency and effectiveness theory as an alternative to models that use sets of experimental parameters through tables and complex abacus, such as the theory of effectiveness ( $\varepsilon$-NUT).

The first aspect deals with the main problem related to heat exchangers: increasing the heat exchange between the two fluids available. The second is to simplify the methodology used in heat exchangers.

Nogueira, É. [1] uses efficiency and effectiveness theory to analyze the thermal performance and tube type condenser. The Freon 134a refrigerant flows through the shell water-based aluminum oxide flows into the tubes at relative saturation pressure. The heat exchanger consists of 36 tubes divided into three central regions for analysis. The three regions contain four tubes in line, with three steps, that is, 12 tubes. Efficiency, effectiveness, and temperature profiles are presented graphically for each of the three regions. Experimental results [2] for vapor pressure equal to 1.2 MPa were used as references for the model's physical compatibility.

Nogueira, E. [2] analyzes the pass's influence in a shell and tube condenser, with an inlet pressure of the refrigerant R134a in the shell equal to 1.2 MPa. The parameters used to analyze thermal performance were efficiency and effectiveness. She argues that thermal performance can be improved with a more significant number of passages in the pipe. In the supersaturated steam region, the heat exchange process is efficient at low mass flow rates but is not effective. She concludes that there is ample room to increase the heat exchanger's efficiency. The fluid's temperature entering the tube and the refrigerant's working pressure are the limiting factors for the heat exchanger's more excellent performance.

Tzong-Shing Lee and Jhen-Wei Mai [3] present experimental work related to a heat pump system and its condenser for heating water. The analyses focused mainly on the condenser's heat transfer performance to operate under high water outlet temperature. Refrigerant R134a was selected as the working refrigerant. The condenser is a type of shell and tube heat exchanger with horizontal deflectors, 48 copper tubes, with 12 tubes in each heat exchanger region.

Adrian Bejan [4] presents a review work to delineate the procedure's steps to minimize entropy generation at the level of system components. One of the additional objectives is to present the fundamental idea that the system's entropy generation rate is equal to the sum of all system components' entropy. If a component's irreversibility is minimized, the component level reduction is present at the general system level.

Ahmad Fakheri [5] provides a solution to define thermal efficiency for heat exchangers based on thermodynamics' second law. He demonstrates that for every real heat exchanger, there is an ideal heat exchanger that has the same average arithmetic difference in temperature and the same ratio of cold to the 
hot fluid inlet temperature. The ideal heat exchanger transfers the maximum amount of heat, generates a minimum amount of entropy, and is more efficient. The presented solution provides a new way for the design and analysis of heat exchangers.

Salah Almurtaji et al. [6] claim that heat exchangers are used in many applications, such as power plants, air conditioning, and domestic water heating, and that thermo-economic considerations impose the need to develop more efficient equipment. The work developed provides a systematic review of nanofluids' use in heat exchangers to improve thermo-hydraulic performance. The authors present an introduction to nanofluids and discuss the influence of thermophysical properties on heat exchangers' performance. They emphasize the importance of nanofluids and how they can significantly increase thermal efficiency.

Gaurav Thakur and Gurpreet Singh [7] argue that the injection of air bubbles, which contributes to increasing the level of turbulence in the flow, is a technique that improves the thermal efficiency in shell and tube heat exchanger. They perform an experimental analysis by injecting air bubbles at the tube entrance with water-based nanofluids $\left(\mathrm{Al}_{2} \mathrm{O}_{3}\right)$ and volumetric fractions equal to $0.1 \%$ and $0.2 \%$. The results demonstrate the heat transfer increases with the volumetric concentration of nanoparticles and the injection of air bubbles, with a relative increase of $25 \%$ to $40 \%$

Yue Sun et al. [8] present numerical simulation in a shell and tube type heat exchanger with inclined trefoil-hole baffles (STHX-IT). The objective of the work is to determine thermal performance. For comparison, another shell and tube heat exchanger with segmental baffles (STHX-SG) is also analyzed. They conclude, among others, that the proposed inclined trefoil-hole baffles (STHX-IT) are effective in improving the performance on the shell side and become an advantageous alternative to the segmental baffles type heat exchanger (STHX-SG) in some industrial applications.

Ahmed A. H. Mostafa et al. [9] perform numerical analysis of shell and tube heat exchangers' performance with segmental deflectors using the Fluent CFD software. The work's objective is to model numerically using computational fluid dynamics tools to obtain heat transfer rate and pressure drop. The focus of the analysis is to study the influence of the segmental deflectors' orientation on the shell's side. The results are sensitive to the selected turbulence model. The investigated cases were carried out for different baffle angles, between $0^{\circ}$ and $60^{\circ}$, and that angles of $30^{\circ}$ provide maximum value for the Nusselt number. They conclude that the optimized design of shell and tube heat exchanger with segmental deflectors is beneficial for energy conservation.

According to Ranendra Roy, Bijan Kumar Mandal [10], the refrigerant R-134a is an alternative to CFC R-12 with similar thermodynamic properties. The work develops a computational procedure to obtain different thermodynamic properties of the refrigerant R-134a, using a FORTRAN code. The authors declare that the implemented formulation data are within acceptable limits for all practical 
purposes.

Ravikanth S. Vajjha, Debendra K. Das [11] argue that Prandtl, Reynolds, and Nusselt for nanofluids influence the convective heat transfer coefficient and that the pumping power depends on the Reynolds number. They perform a comprehensive analysis to assess the effects on nanofluids' thermal and hydraulic performance as a function of variations in density, specific heat, thermal conductivity, and viscosity. They conclude that nanoparticles' addition increases viscosity and thermal conductivity moderately and that specific heat and density change modestly.

\section{Objective}

The work's objective is to analyze the influence of the saturation temperature of the R134a refrigerant on the thermal performance of a shell and tube type condenser, with aluminum oxide $\left(\mathrm{Al}_{2} \mathrm{O}_{3}\right)$ nanoparticles flowing into the tubes. For analysis, the heat exchanger is subdivided into three regions: subcooled liquid, saturated steam, and superheated steam. The parameters used to analyze the performance are efficiency and effectiveness, through variations of quantities such as saturation temperature, the mass flow of the nanofluid, fraction in the nanoparticles' volume, and the number of passes in the tube in the regions the heat exchanger.

\section{Methodology}

The heat condenser consists of three regions: superheated steam I, saturated steam II and subcooled liquid III, represented by Figure 1. There are four tubes inline in each region and three passages into the tube for the analysis standard. There are three horizontal baffles in the supersaturated steam region. The fluid flow rate in the tube varies from $0.12 \mathrm{~kg} / \mathrm{s}$ to $0.50 \mathrm{~kg} / \mathrm{s}$. The steam flow rate is equal to $0.20 \mathrm{~kg} / \mathrm{s}$. The properties of the water, refrigerant, and nanoparticles are shown in Table 1.

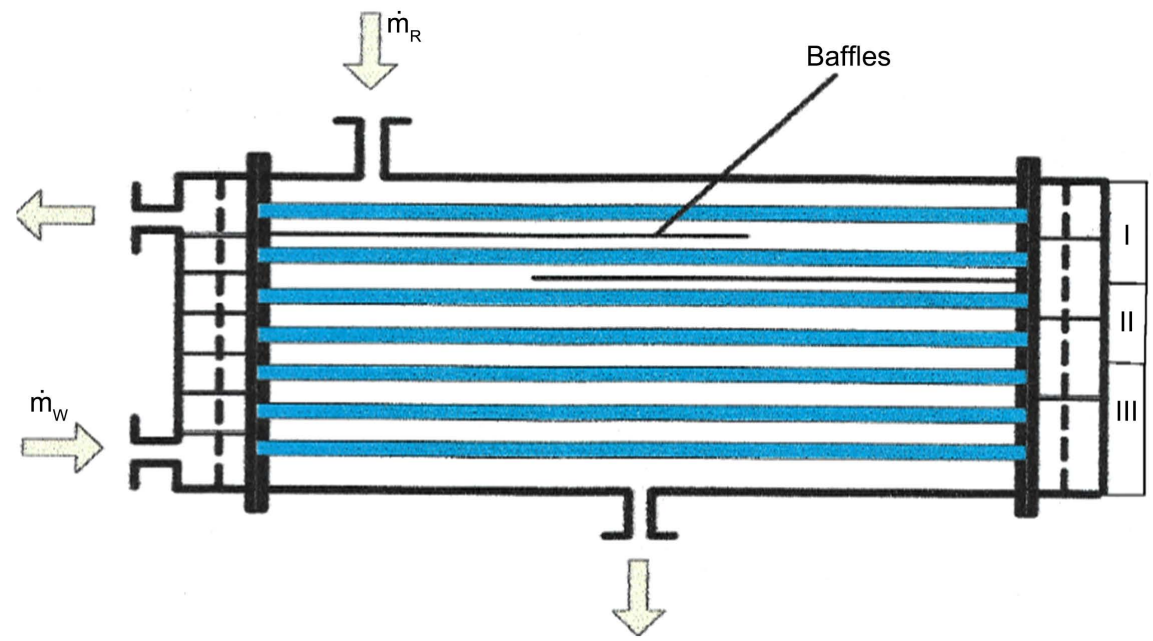

Figure 1. Scheme for the shell and tubes condenser. 
Table 1. Properties of the fluids and nanoparticle.

\begin{tabular}{|c|c|c|c|c|}
\hline \multirow{2}{*}{ Properties } & \multicolumn{2}{|c|}{ Freon R134a } & \multirow{2}{*}{ Water } & \multirow{2}{*}{$\mathrm{Al}_{2} \mathrm{O}_{3}$} \\
\hline & I & III & & \\
\hline$k \mathrm{~W} /\left(\mathrm{m}^{\circ} \mathrm{C}\right)$ & 15.447 & 74.716 & 0.60 & 31.922 \\
\hline$C p \mathrm{~J} /\left(\mathrm{kg}^{\circ} \mathrm{C}\right)$ & 1144.5 & 1498.4 & 4180 & 837.336 \\
\hline$\mu \mathrm{kg} /(\mathrm{m} \cdot \mathrm{s})$ & $12.373 \times 10^{-6}$ & $161.45 \times 10^{-6}$ & $0.758 \times 10^{-3}$ & $4.65 \times 10^{-5}$ \\
\hline$P \mathrm{~kg} / \mathrm{m}^{3}$ & 50.085 & 1146.7 & 997 & 3950 \\
\hline$v \mathrm{Nm}^{2} / \mathrm{s}$ & $2.47 \times 10^{-7}$ & $0.14 \times 10^{-6}$ & $0.8 \times 10^{-7}$ & $0.118 \times 10^{-7}$ \\
\hline$a \mathrm{~m}^{2} / \mathrm{s}$ & $2.695 \times 10^{-4}$ & $4.35 \times 10^{-5}$ & $1.43 \times 10^{-7}$ & $9.65 \times 10^{-6}$ \\
\hline $\operatorname{Pr}$ & 1091.1 & 310.7 & 5.68 & 818 \\
\hline
\end{tabular}

The standard and initial input data for each of the regions are:

TREntr $=100^{\circ} \mathrm{C}$-Inlet temperature of refrigerant R134a

TWEntr $=25^{\circ} \mathrm{C}-$ Nanofluid inlet temperature

Tsat $=81.0^{\circ} \mathrm{C}$-Steam saturation temperature

$$
\begin{gathered}
\text { NTube }=4 \\
\text { Npass }=3 \\
D_{W}=0.0127 \mathrm{~m} \\
L=0.762 \mathrm{~m} \\
B=0.0145 \mathrm{~m} \\
C L=1.0 \\
C T P=0.85
\end{gathered}
$$

So, we have:

$$
\begin{gathered}
P t=1.25 D_{W} \\
D e=\left(1.27 / D_{W}\right)\left(P t^{2}-0.785 D_{W}^{2}\right) \\
D c=3.0 D_{W} \\
P R=P t / D_{W} \\
A_{W}=\pi D_{W} \text { LNtubeNpass } \\
D s=0.637 \sqrt{C L / C T P} \sqrt{(\text { ATPR D }) / L} \\
A s=D s B\left(1.0-D_{W} / P t\right)
\end{gathered}
$$

$A_{W}$ is the heat exchange area, $A s$ is the shell-side pass area. $D s$ is the shell diameter. $P t$ is the tube pitch. $D_{W}$ is the tube diameter. $D e$ is the equivalent hydraulic diameter. $B$ is the baffles spacing.

$$
\begin{gathered}
R e_{R}=\left(\dot{m}_{R} D e\right) /\left(A s \mu_{R}\right) \\
N u_{R}=0.36 \operatorname{Re}_{R}^{0.55} \operatorname{Pr}_{R}^{1 / 3}
\end{gathered}
$$

at where, $\dot{m}_{R}$ is the mass flow, $\mu_{R}$ is the dynamic viscosity of the refrigerant, 
$R e_{R}$ is the Reynolds number, $P r_{R}$ is the Prandtl number and $N u_{R}$ is the Nusselt number.

$$
h_{R}=\left(N u_{R} k_{R}\right) / D e
$$

$k_{R}$ is the thermal conductivity and $h_{R}$ is the convection heat transfer coefficient.

$$
\begin{gathered}
\rho_{W}=\phi \rho_{A l}+(1.0-\phi) \rho_{W} \\
\mu_{W}=\mu_{W} *(1.0+2.5 \phi) \\
v_{W}=\mu_{W} / \rho_{W} \\
C p_{W}=\left(\phi \rho_{A l} C p_{A l}+(1.0-\phi) \rho_{W} C p_{W}\right) / \rho_{W} \\
k_{W}=\left(K_{A l}+2 k_{W}+2\left(k_{A l}-k_{W}\right)(1+0.1)^{3} \phi\right) /\left(K_{A l}+2 k_{W}-\left(k_{A l}-k_{W}\right)(1+0.1)^{2} \phi\right) k_{W} \\
\alpha_{W}=k_{W} /\left(\rho_{W} C p_{W}\right) \\
\operatorname{Pr}_{W}=\alpha_{W} / v_{W}
\end{gathered}
$$

at where $\rho_{W}$ is the density of the fluid, $\mu_{W}$ is the dynamic viscosity of the fluid, $v_{W}$ is the kinematic viscosity of the fluid, $C p_{W}$ is the specific heat of the fluid, $k_{W}$ is the thermal conductivity and $P r_{W}$ is Prandtl number.

$$
\begin{gathered}
\dot{m}_{W T}=\dot{m}_{W} / N_{\text {Tube }} \\
R e_{W}=\left(4 \dot{m}_{W} T\right) /\left(\pi D_{W} \mu_{W}\right)
\end{gathered}
$$

at where $\dot{m}_{W}$ is the flow inlet of the fluid, $\dot{m}_{W T}$ is the flow in each tube and $R e_{W}$ is the Reynolds number.

$$
\begin{gathered}
N u_{W}=4.364+\left(0.0722 R e_{W} P r_{W} D_{W}\right) / L \text { for } R e_{W} \leq 2100 \\
N u_{W}=\left[\left(R e_{W}-2100\right) /\left(10^{4}-2100\right)\right]\left[0.027\left(10^{4}\right)^{0.8} \operatorname{Pr}_{W}^{1 / 3}\right. \\
\left.-4.364+\left(0.0722(2100) P r_{W} D_{W}\right) / L\right] \\
-4.364+\left(0.0722(2100) P r_{W} D_{W}\right) / L \text { for } 2100<R e_{W} \leq 10^{4} \\
N u_{w}=0.027 R e_{w}^{0.8} \operatorname{Pr}_{w}^{1 / 3} \text { for } R e_{W}>10^{4} \\
h_{W}=\left(N u_{W} K_{W}\right) / D_{W} \\
U_{O}=1 /\left(1 / h_{R}+1 / h_{W}\right)
\end{gathered}
$$

at where $U_{O}$ is the global heat transfer coefficient.

$$
\begin{gathered}
C_{R}=\dot{m}_{R} C p_{R} \\
C_{W}=\dot{m}_{W} C p_{W} \\
N T U=\left(A_{W} U_{O}\right) / C m i n \\
F a=(N T U / 2)\left(1-C_{*}\right) \\
C_{*}=C \text { min } / \text { Cmax }
\end{gathered}
$$

$C_{R}$ is the thermal capacity of the refrigerant, $C_{W}$ is the thermal capacity, $N T U$ is called the Number of Thermal Units, Cmin is the smallest of the specific heats. 


$$
\begin{gathered}
\sigma_{T}=\operatorname{Tanh}(F a) / F a \\
\eta_{T}=1 /\left(1 /\left(\sigma_{T} N T U\right)+\left(1+C_{*}\right) / 2\right)
\end{gathered}
$$

$\sigma_{T}$ is thermal efficiency and $\eta_{T}$ is the thermal effectiveness.

\subsection{Subcooled Liquid}

Solution procedure for Region I:

$$
\begin{gathered}
T W_{i}=\text { TWEntr } \\
T R_{i}=T \text { sat } \\
Q_{\text {Actual }}=\left(T R_{i}-T W_{i}\right) C \min /\left(1 /\left(\sigma_{T} N T U\right)+\left(1+C_{*}\right) / 2\right) \\
T W_{o}=\left(Q_{\text {actual }} / C_{W}\right)+T W_{i} \\
T R_{o}=T R_{i}-\left(Q_{\text {Actual }} / C_{R}\right)
\end{gathered}
$$

at where, $Q_{\text {Actual }}$ is the heat exchange between fluids, $T W_{i}$ is the fluid inlet temperature, Tsat is a saturation temperature.

\subsection{Saturated Steam}

Table 2 below shows the enthalpies for saturated steam and saturated liquid for each of the saturation temperatures used in determining the results.

Solution procedure for Region II:

$$
T W_{i}=T W_{o}
$$

at where $T W_{o}$ is the output temperature of the fluid in the region I.

Do it:

$$
\begin{gathered}
X=0.0 \\
h l v=h v-h l \\
\mu_{R}=\mu_{R l} X+\mu_{R V}(1 . d 0-X) \\
\rho_{R}=\rho_{R l} X+\rho_{R V}(1 . d 0-X) \\
k_{R}=k_{R l} X+k_{R V}(1 . d 0-X) \\
C p_{R}=C p_{R L} X+C p_{R V}(1 . d 0-X) \\
\operatorname{Pr}_{R}=\operatorname{Pr}_{R l} X+\operatorname{Pr}_{R V}(1 . d 0-X)
\end{gathered}
$$

at where $X$ is the steam fraction in Region II.

Table 2. Enthalpies of saturated steam $(h v)$ and saturated liquid $(h l)$.

\begin{tabular}{ccc}
\hline ssat $-{ }^{\circ} \mathrm{C}$ & $h \boldsymbol{h}-\mathrm{kW} /(\mathrm{kg} \cdot \mathrm{K})$ & $h l-\mathrm{kW} /(\mathrm{kg} \cdot \mathrm{K})$ \\
\hline 81.0 & 312.072 & 182.210 \\
71.8 & 302.088 & 156.809 \\
64.7 & 294.074 & 148.335 \\
55.2 & 284.074 & 132.545 \\
\hline
\end{tabular}




$$
\begin{gathered}
R e_{R}=\left(\dot{m}_{R} D e\right) /\left(A s \mu_{R}\right) \\
\Delta_{f}=T s a t-T_{R E f} \\
h_{R}=0.943\left(\left(k_{R} \rho_{R} g h l v\right) /\left(\mu_{R} D s \Delta_{f}\right)\right)^{0,25}
\end{gathered}
$$

at where, $R e_{R}$ is the number of Reynolds in Region II, $\Delta f$ is a reference temperature difference, $h_{R}$ is the convection heat transfer coefficient, and $T_{R E f}=T w_{i}$.

$h_{R}$ varies with properties. The heat exchange between fluids in Region II is achieved by:

$$
\begin{gathered}
\sigma_{T}=\operatorname{Tanh}(F a) / F a \\
\eta_{T}=1 /\left(1 /\left(\sigma_{T} N T U\right)+\left(1+C_{*}\right) / 2\right) \\
Q_{\text {Actual }}=\left(T \text { sat }-T W_{i}\right) \operatorname{Cmin} /\left(1 /\left(\sigma_{T} N T U\right)+\left(1+C_{T}\right) / 2\right) \\
T W=T W_{i}+\left(Q_{\text {Actual }} / C_{W}\right)
\end{gathered}
$$

Return to Equation 60 and recalculate $Q_{\text {Actuar }} T W$.

The procedure at Region II ends when:

$$
X \leq 1.0
$$

\subsection{Superheated Steam}

Solution procedure for Region III:

$$
\begin{gathered}
T W_{i}=T W_{o} \\
T R_{i}=100^{\circ} \mathrm{C}
\end{gathered}
$$

at where $T W_{o}$ is the output temperature of the fluid in region II.

$$
\begin{gathered}
\sigma_{T}=\operatorname{Tanh}(F a) / F a \\
\eta_{T}=1 /\left(1 /\left(\sigma_{T} N T U\right)+\left(1+C_{*}\right) / 2\right) \\
Q_{\text {Actual }}=\left(T R-T W_{i}\right) C \min /\left(1 /\left(\sigma_{T} N T U\right)+\left(1+C_{*}\right) / 2\right) \\
T W=T W_{i}+\left(Q_{\text {Actual }} / C_{W}\right)
\end{gathered}
$$

\section{Results and Discussion}

\subsection{Subcooled Liquid}

In this subsection, we present some results related to the subcooled liquid region. The fluid inlet temperature in the tubes is equal to $25^{\circ} \mathrm{C}$, and the refrigerant inlet temperature is equal to the saturation temperature (Tsat). The original number of the pass in the tube is equal to 3. New numbers of the pass in the tube have been added for analysis of efficiency and effectiveness. The results obtained include global heat transfer coefficient, efficiency, effectiveness, temperature profile for the fluid in the tubes, the temperature profile of the refrigerant in the shell, and the outlet temperatures. The volume fraction of nanoparticles ranges 
from 0 to 0.20 , and the number of passes through the tube varies from 3 to 12 .

The variation of the global convective heat transfer coefficient as a function of the volume fraction of the aluminum oxide nanoparticles $\left(\mathrm{Al}_{2} \mathrm{O}_{3}\right)$, for the number of the pass in the tube equal to 3 , is represented by Figure 2. The global heat transfer coefficient practically doubles at the nanofluid's low flow rate when the volume fraction is equaled to 0.20 . However, the ratio is significantly less than $200 \%$ for high flow rates, with a relative increase of close to $2.2 \%$.

Figure 3 and Figure 4 show the efficiency and effectiveness, respectively, as a function of the nanofluid's mass flow rate. Efficiency is high in all situations analyzed. However, effectiveness is shown below 0.42 for three passes in the tube. It is evident that there are margins for increasing effectiveness, and one of the options is to increase the number of the pass in the tube.

Figure 5 shows the effectiveness versus the efficiency for the number of passes in the tube varying from 3 to 12 . The effectiveness increases significantly when the number of steps in the tube goes up from 3 to 12 . It goes up from 0.4 to 0.76 when the fraction in the nanoparticles' volume is equal to 0.10. In contrast, efficiency remains high, varying from 0.88 to 0.98 when the number of a pass in the tube is equal to 12 . The highest value for efficiency is related to nanofluid's lower flow, as shown in Figure 3.

Figure 6 and Figure 7 show outlet temperatures for nanofluid and refrigerant for two temperatures if saturation, namely, $T s a t=81.0^{\circ}$ and $T s a t=55.2^{\circ} \mathrm{C}$, in the standard configuration. The outlet temperatures in the subcooled fluid region are higher for lower flow rates of the nanofluid since the thermal capacities, in these cases, are lower. Higher fractions of nanoparticles enable lower outlet temperatures for the nanofluid since the specific heat increases, and the nanofluid absorbs a more significant fraction of the energy involved. In contrast, lower outlet temperatures are obtained for pure water in the refrigerant and approach the nanofluid's inlet temperature. A lower value for saturation temperature allows lower refrigerant outlet temperature at all flow rates.

In summary, in the subcooled liquid region, there are:

- Higher values for the global convective heat transfer coefficient for larger fractions of nanoparticles;

- High efficiency for all situations analyzed;

- Low effectiveness in the standard configuration of the heat exchanger, regardless of the fraction of nanoparticles;

- High effectiveness for the number of passes in the tube equal to 12, with relevance for higher flow rates and higher fractions of nanoparticles;

- Higher nanofluid outlet temperatures for higher saturation temperatures and lower nanoparticle fractions, without significant relevance to the nanofluid flow rate variation;

- Lower refrigerant outlet temperatures for lower saturation temperatures and lower fractions of nanoparticles without significant relevance to the nanofluid flow rate variation. 


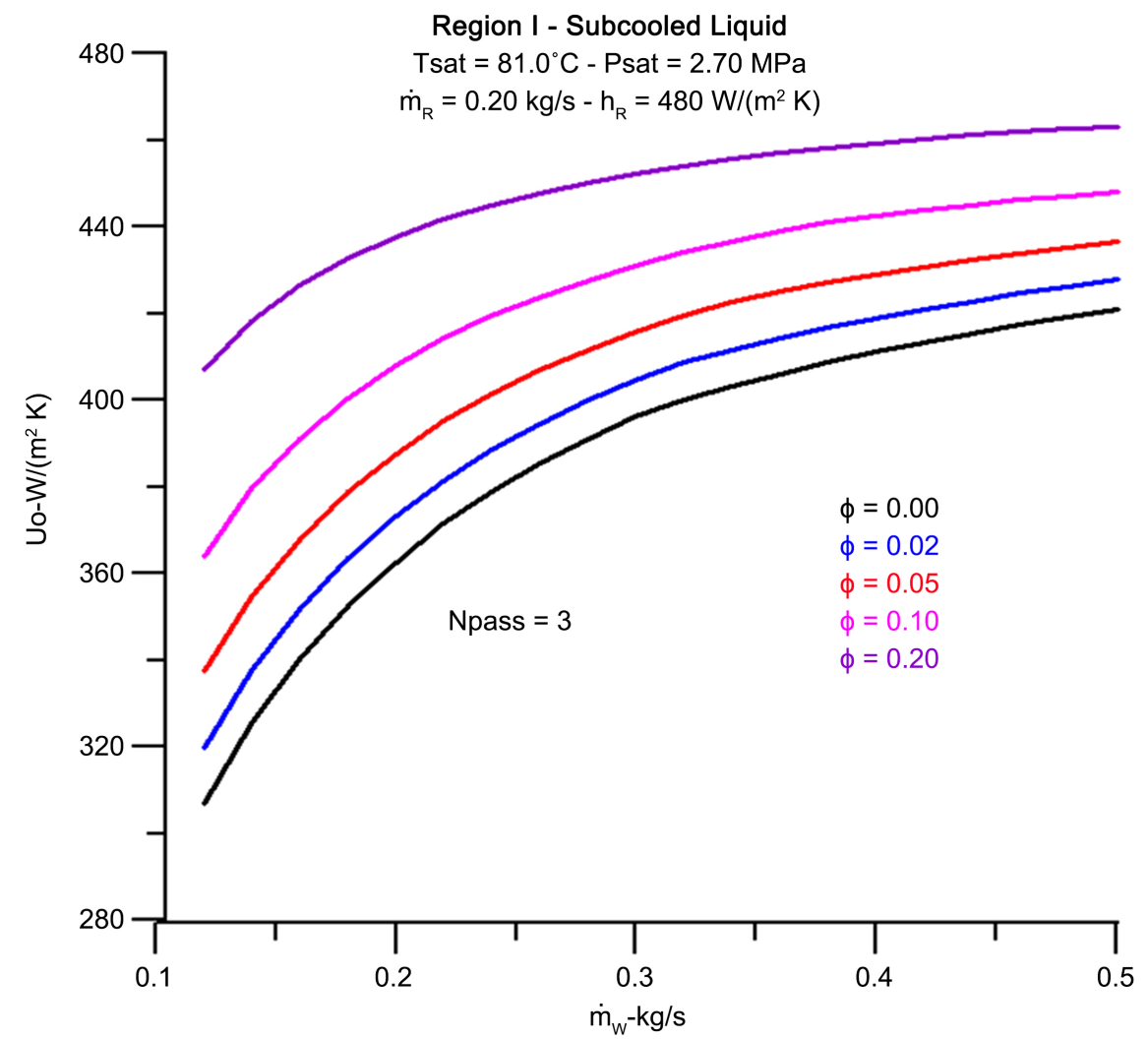

Figure 2. Global heat transfer coefficient versus mass flow rate of the nanofluid.

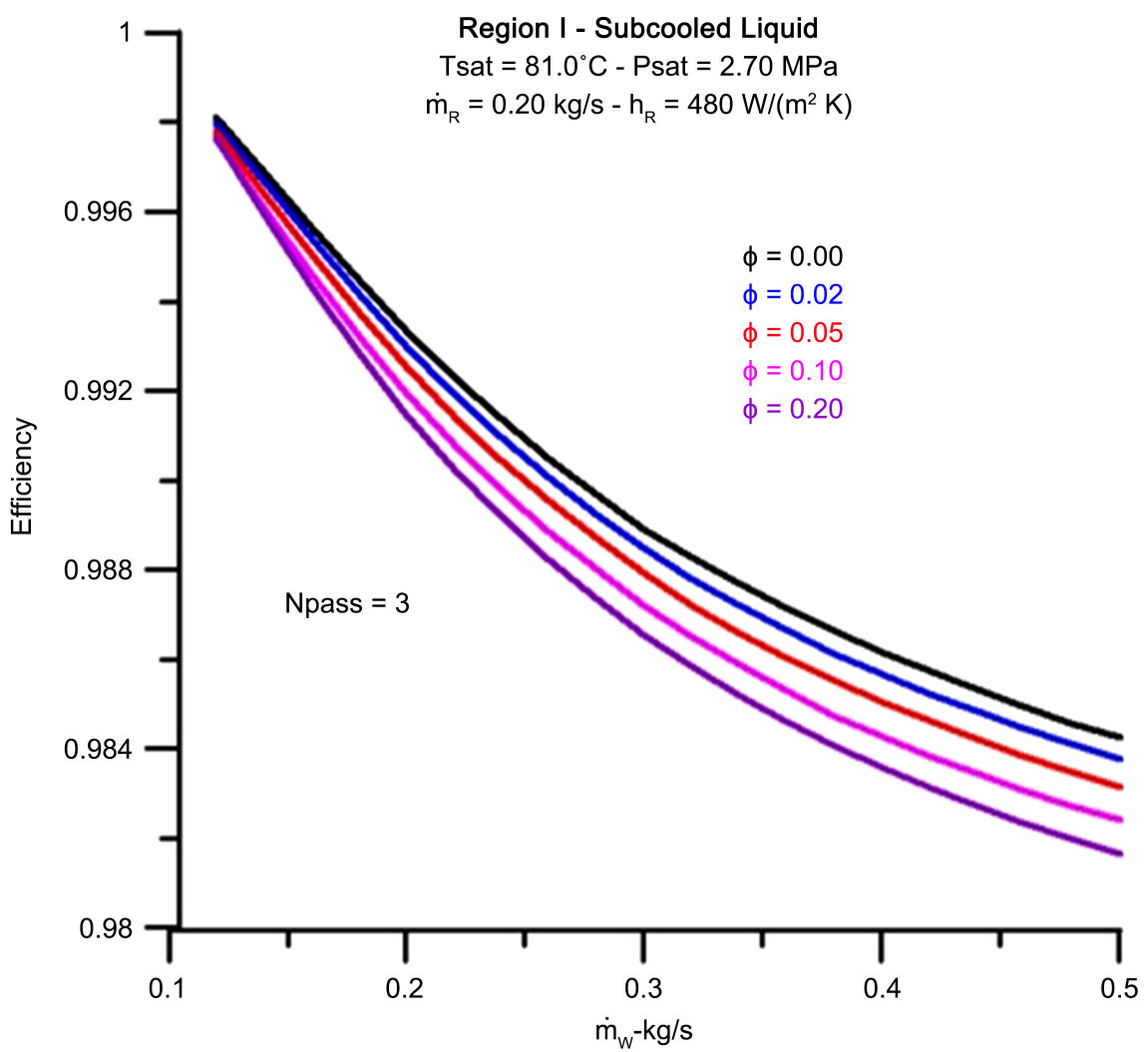

Figure 3. Efficiency versus mass flow rate of the nanofluid. 


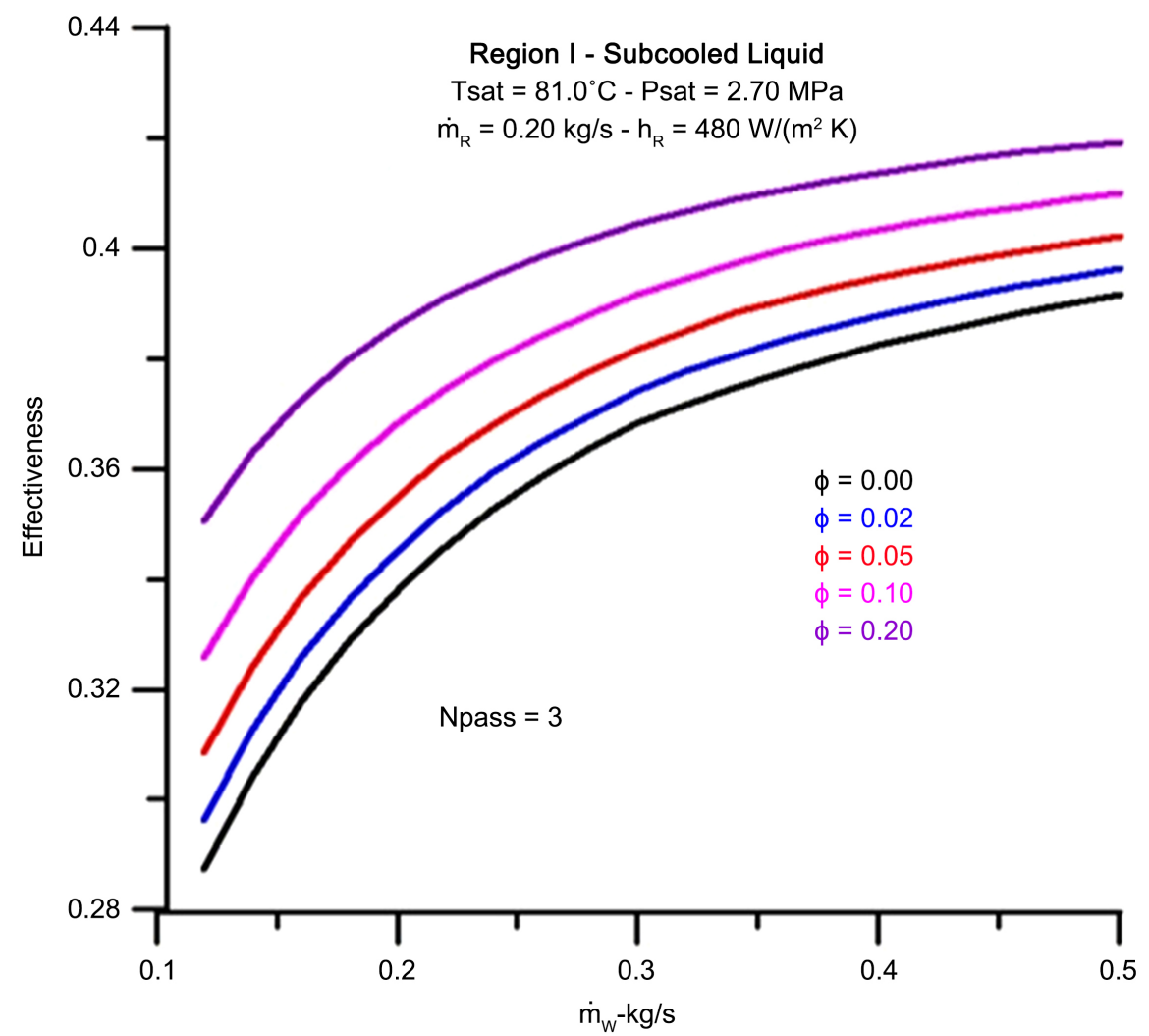

Figure 4. Effectiveness versus mass flow rate of the nanofluid.

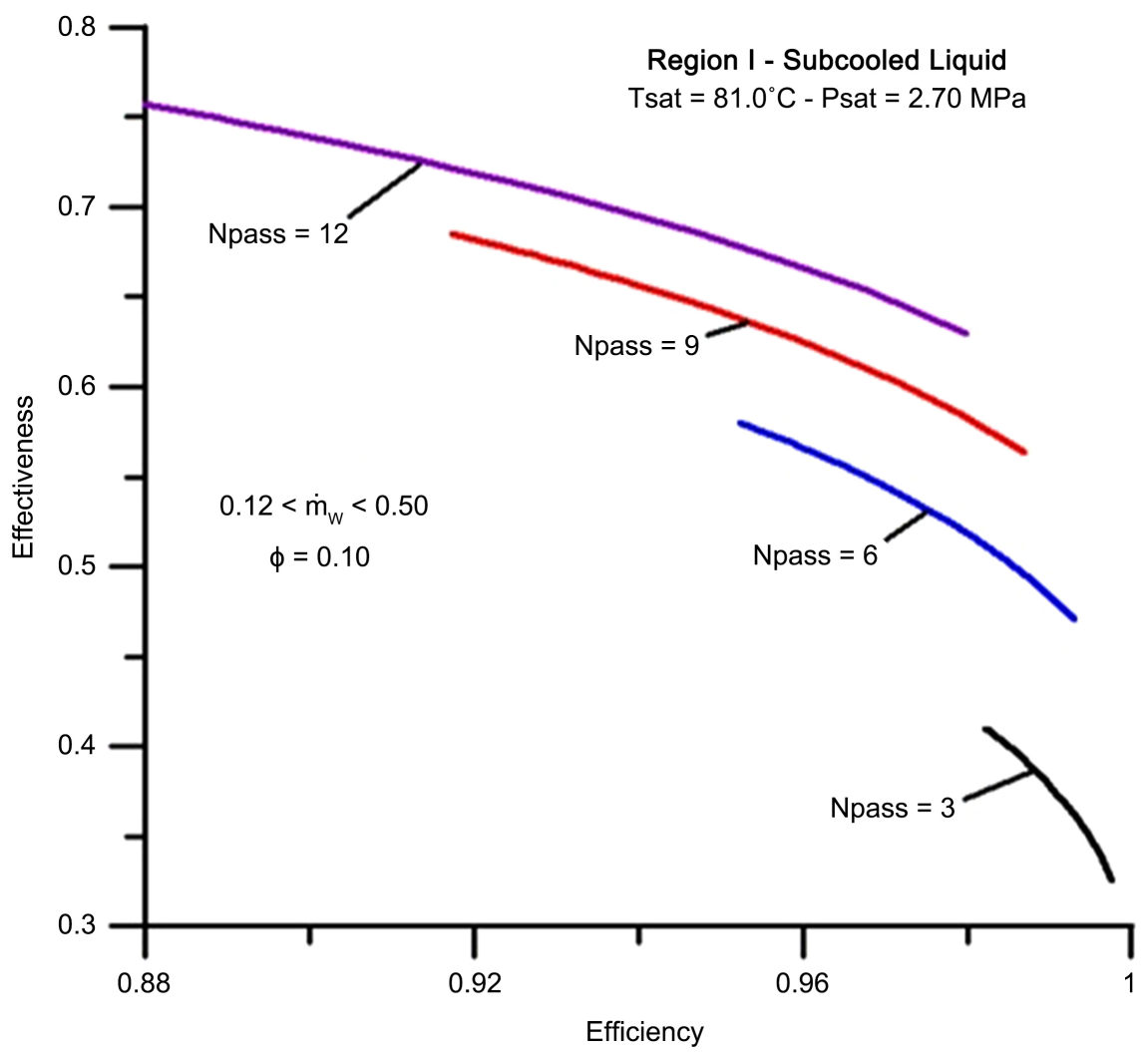

Figure 5. Effectiveness versus efficiency for a fraction of nanoparticles equal 0.10. 


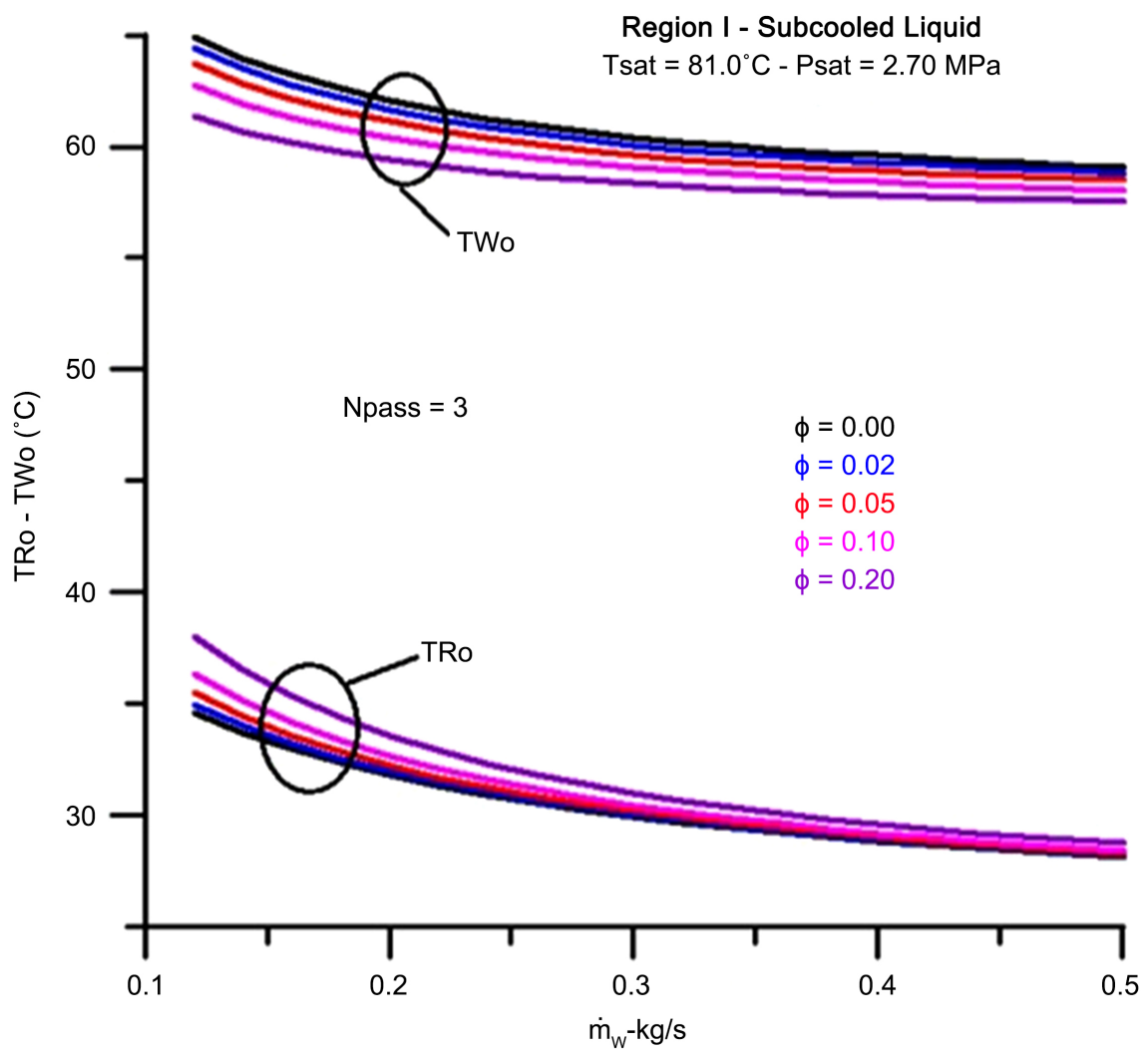

Figure 6. Output temperatures versus mass flow rate of the nanofluid $\left(T s a t=81.0^{\circ} \mathrm{C}\right.$ ).

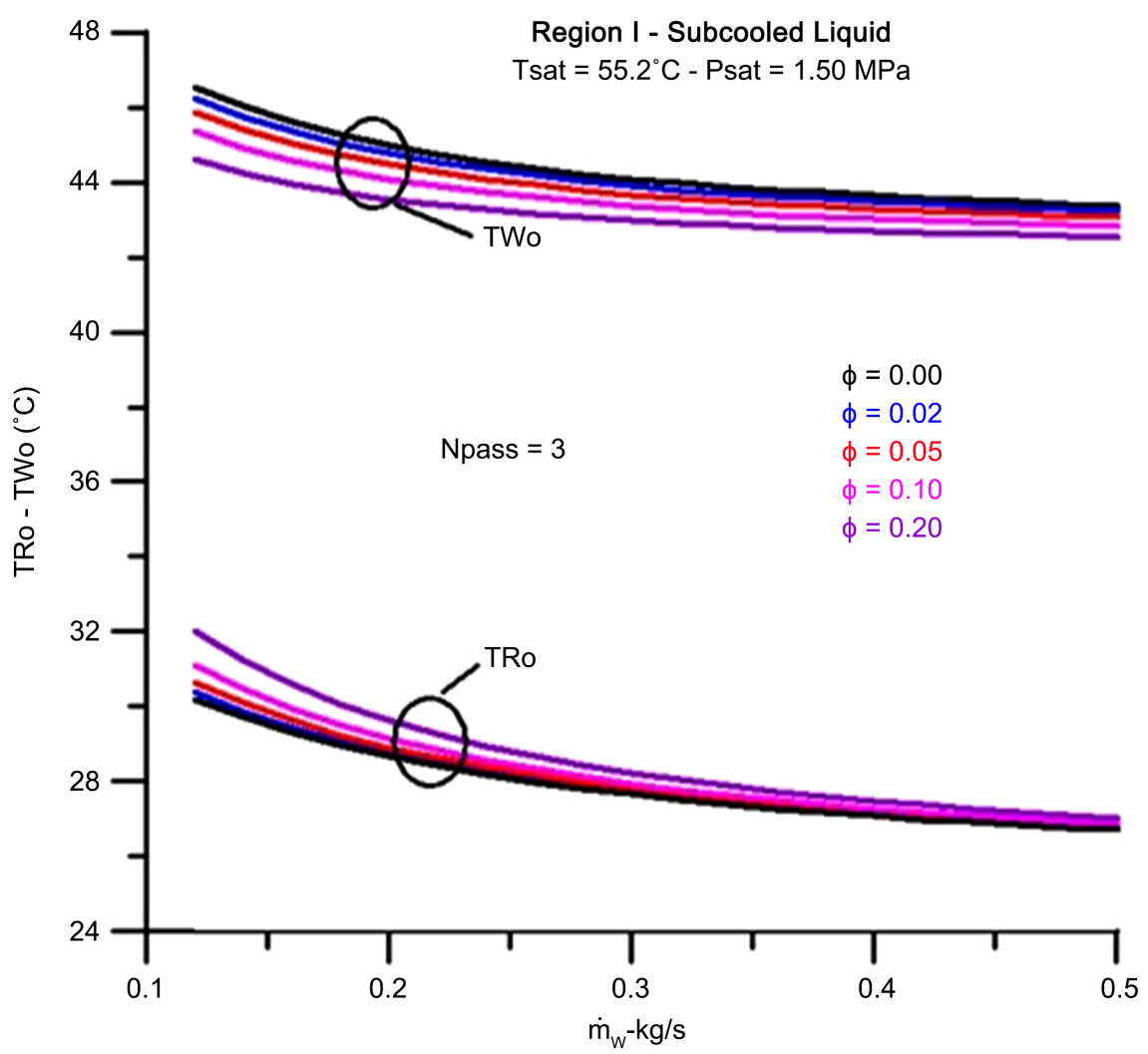

Figure 7. Output temperatures versus mass flow rate of the nanofluid $\left(T s a t=55.2^{\circ} \mathrm{C}\right)$. 


\subsection{Saturated Steam}

In this subsection, we present some results related to the saturated steam region. The fluid inlet temperature in the tubes is equal to the subcooled liquid region's outlet temperature, whit the inlet and outlet temperatures of the refrigerant equal to the saturation temperature (Tsat). The original number of the pass in the tube is equal to 3 and has no variation in this case. The results obtained include convective global heat transfer coefficient, efficiency, effectiveness, temperature profile, and nanofluid outlet temperatures. The volume fraction of nanoparticles ranges from 0 to 0.20 .

Figure 8 shows the value for the enthalpy of saturated liquid $(h I)$ and saturated steam $(h v)$ as a function of the saturation temperature of refrigerant R134a. The polynomial functions used in the interpolation are explicitly in the figure.

Figure 9 presents results for the global convection heat transfer coefficient as a function of the vapor fraction, with a mass flow of the nanofluid as a parameter, for two nanoparticles' fractions. The global convection coefficient increases significantly for a high fraction of nanoparticles in all mass flow rates.

Figure 10 and Figure 11 show results for efficiency and effectiveness as a function of the refrigerant vapor fraction. Efficiency is high for lower mass flow rates of the nanofluid and significantly low for high flow rates. Larger fractions of nanoparticles show less efficiency for the same mass flow of the nanofluid. In contrast, the effectiveness is lower for the nanofluid's lower mass flow rates since there is less absorption of the steam's energy. The effectiveness is close to the maximum possible for high mass flow rates of the nanofluid, regardless of the nanoparticles' volume fraction. Larger fractions in the nanoparticles' volume increase efficiency since more significant absorption of the energy is available through steam.

Figure 12 summarizes the discussions above, demonstrating that the efficiency is close to the maximum possible for the nanofluid's higher mass flow rates.

Figure 13 shows the temperature profile of the nanofluid as a function of the steam fraction. The nanofluid's lower mass flow rates enable higher outlet temperatures since the fluid has less thermal capacity and absorbs less available energy. In contrast, nanofluids with higher mass flow rates and higher nanoparticle fractions have lower outlet temperatures with higher thermal capacities.

Figure 14 and Figure 15 show the nanofluid outlet temperatures for two saturation temperatures: $81.0^{\circ} \mathrm{C}$ and $55.2^{\circ} \mathrm{C}$. As the thermal capacity at lower flow rates is lower, the greater the temperature differences between inlet and outlet in the sub-region. The nanofluid outlet temperatures practically do not depend on the fraction of nanoparticles for lower flow rates. However, for higher nanofluid flow rates, the fraction of nanoparticles has a significant influence.

In summary, in the saturated steam region, there are:

- The global convection coefficient increases significantly for a high fraction of nanoparticles in all mass flow rates;

- Efficiency is high for lower mass flow rates of the nanofluid and significantly low for high flow rates; 


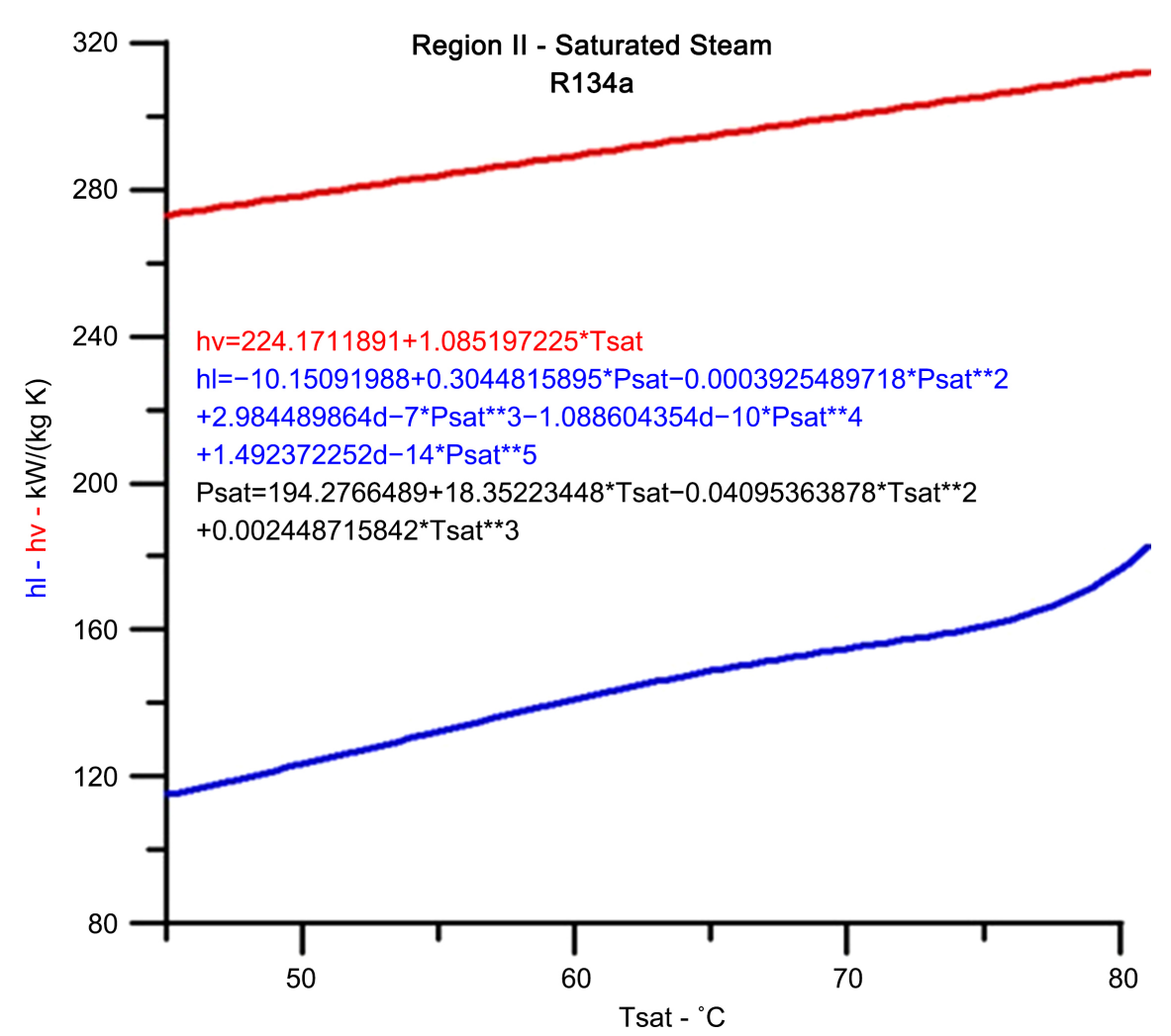

Figure 8. Enthalpy of liquid and saturated steam versus saturation temperature.

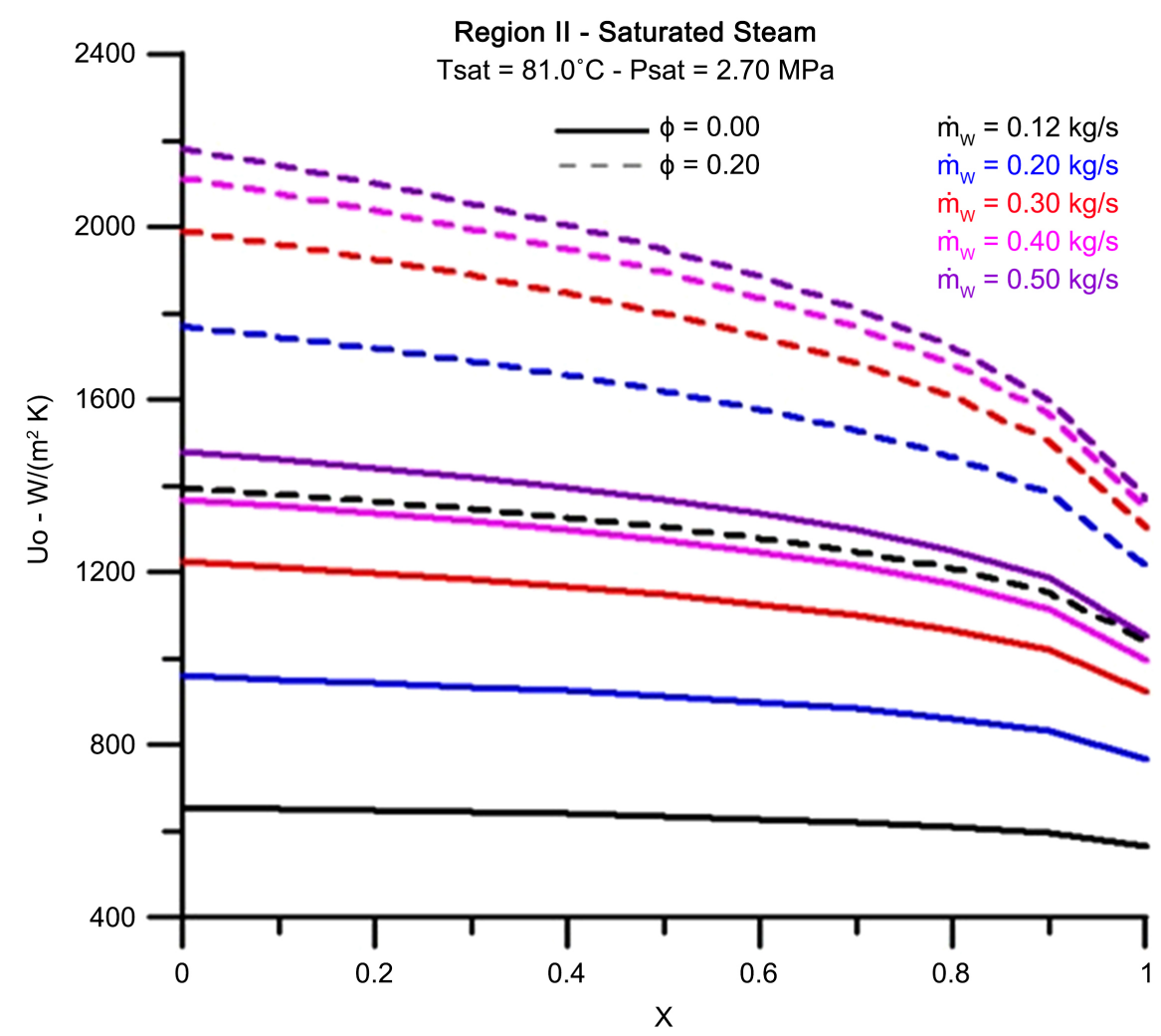

Figure 9. Coefficient of global convective heat transfer versus the fraction of vapor and mass flow rate of the nanofluid as a parameter. 


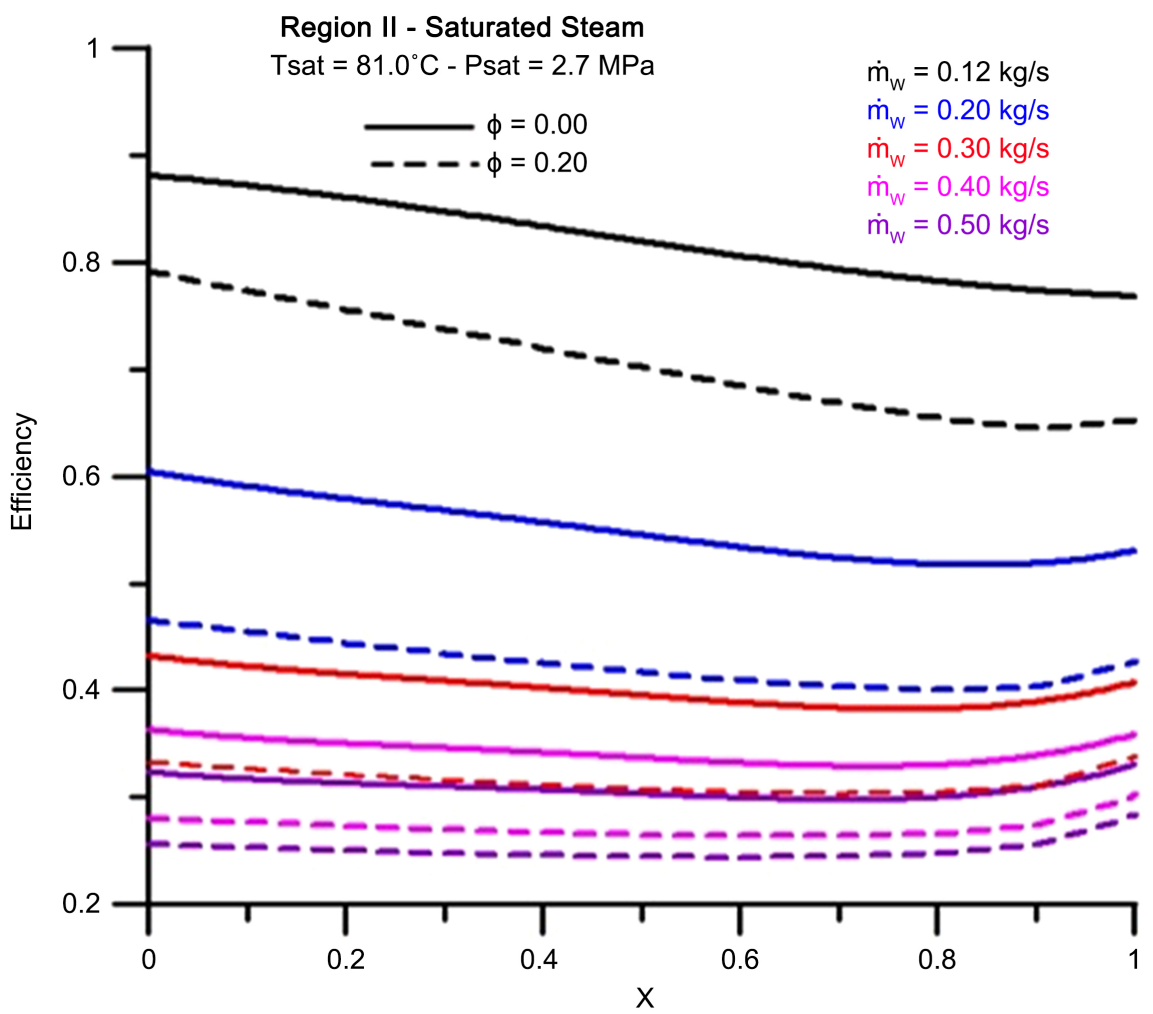

Figure 10. Efficiency versus the fraction of vapor and mass flow rate of the nanofluid as a parameter.

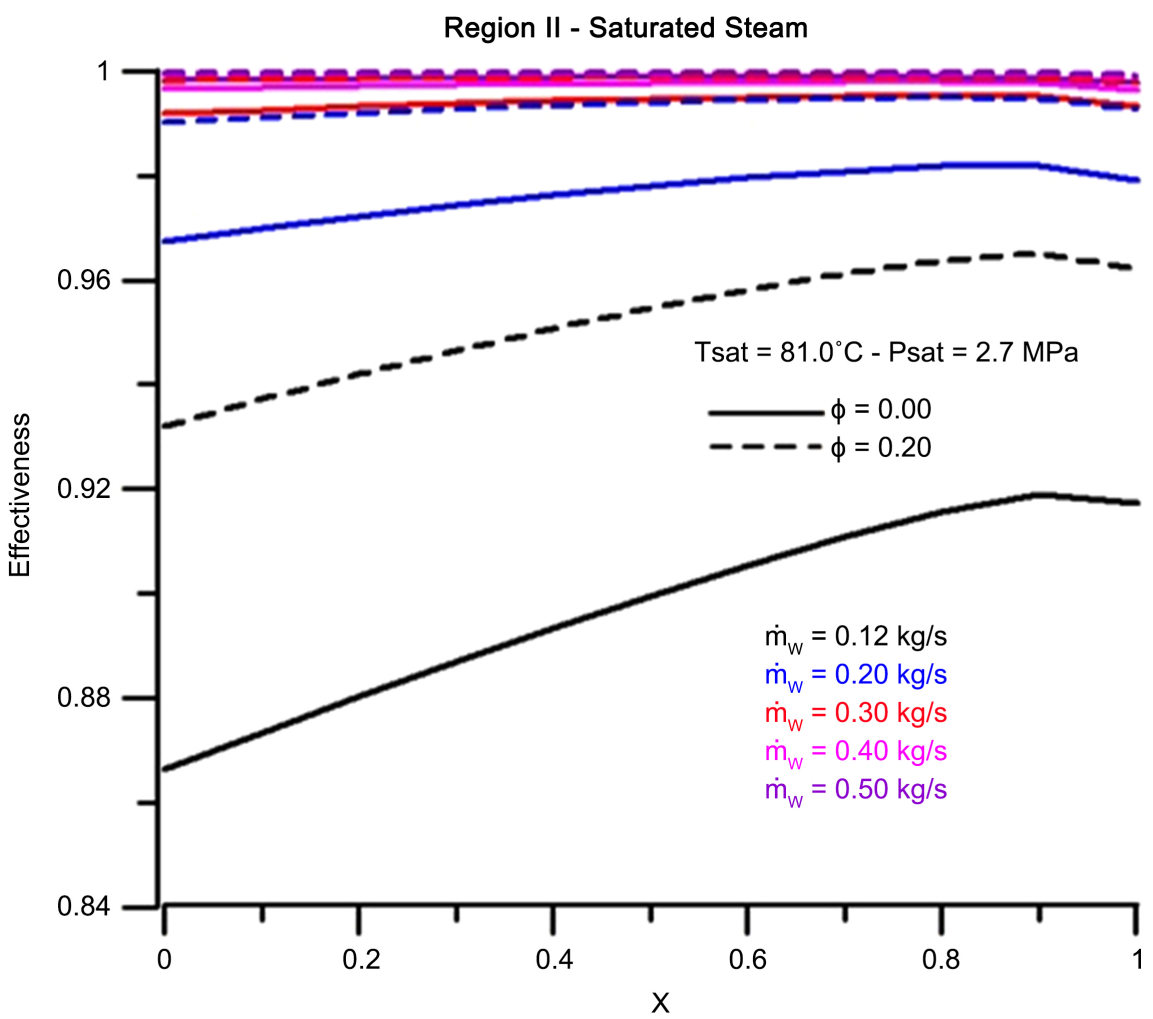

Figure 11. Effectiveness versus the fraction of vapor and mass flow rate of the nanofluid as a parameter. 


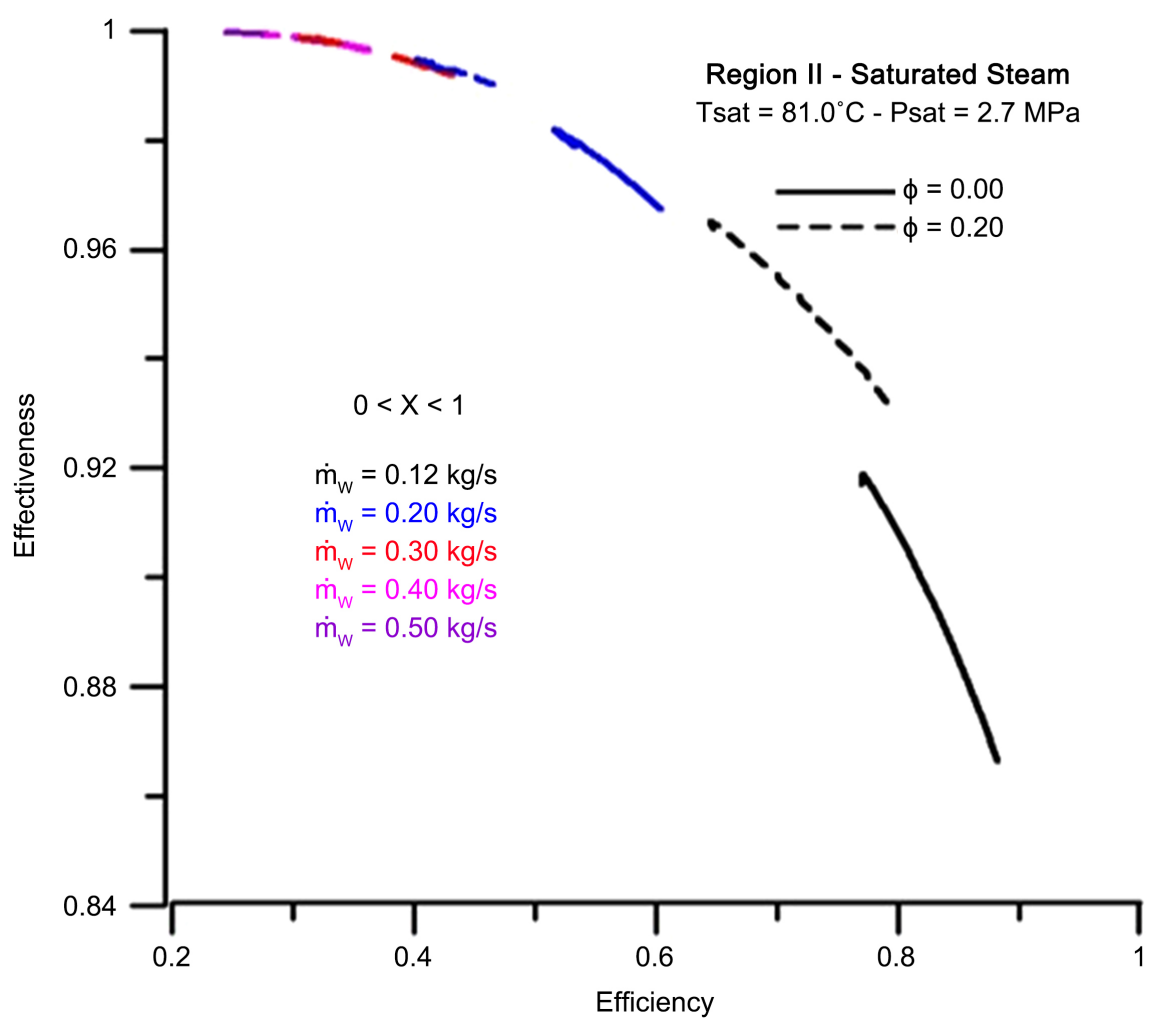

Figure 12. Effectiveness versus efficiency and mass flow rate of the nanofluid as a parameter.

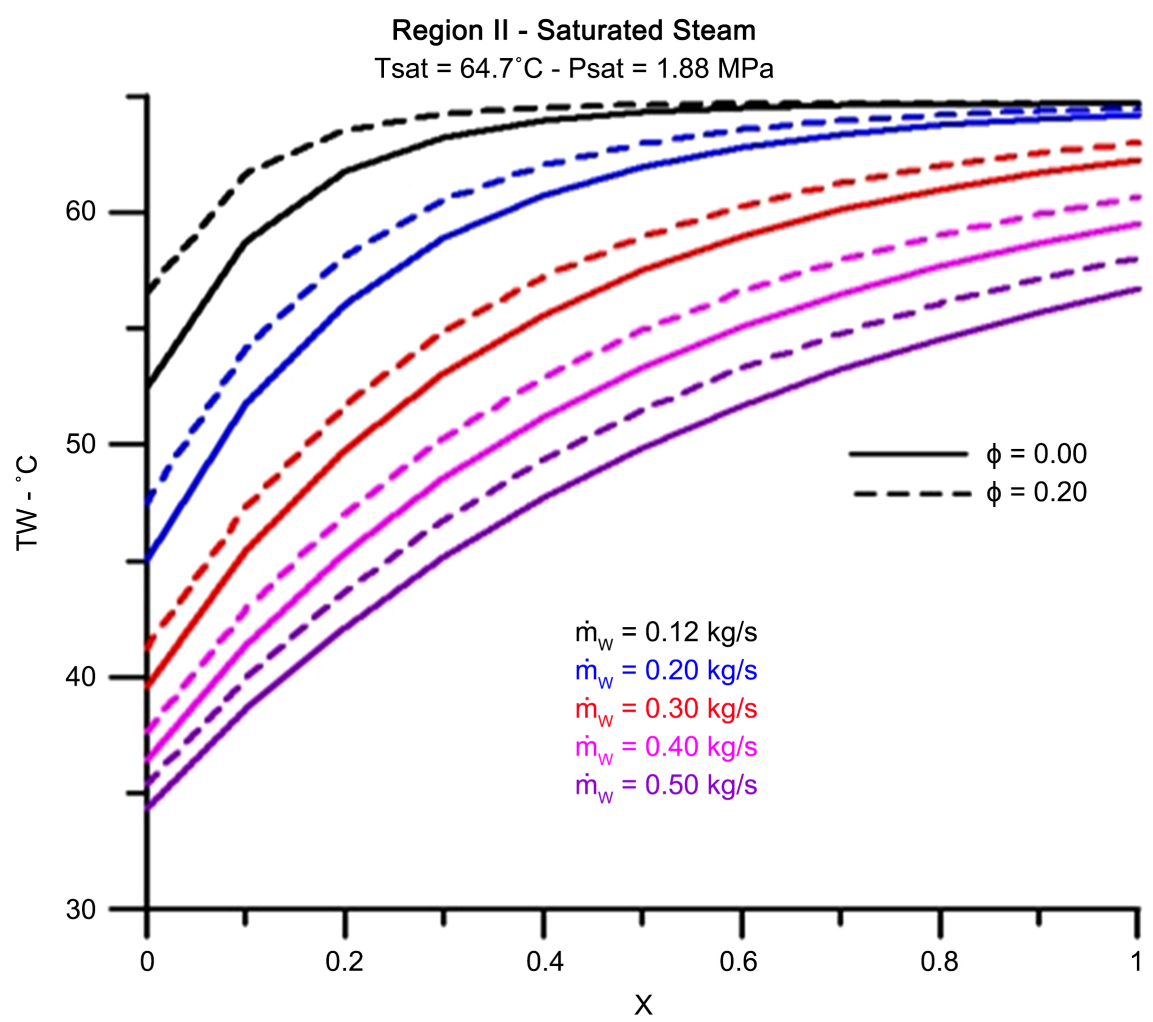

Figure 13. Nanofluid temperature profile versus vapor fraction and mass flow rate of the nanofluid as a parameter. 


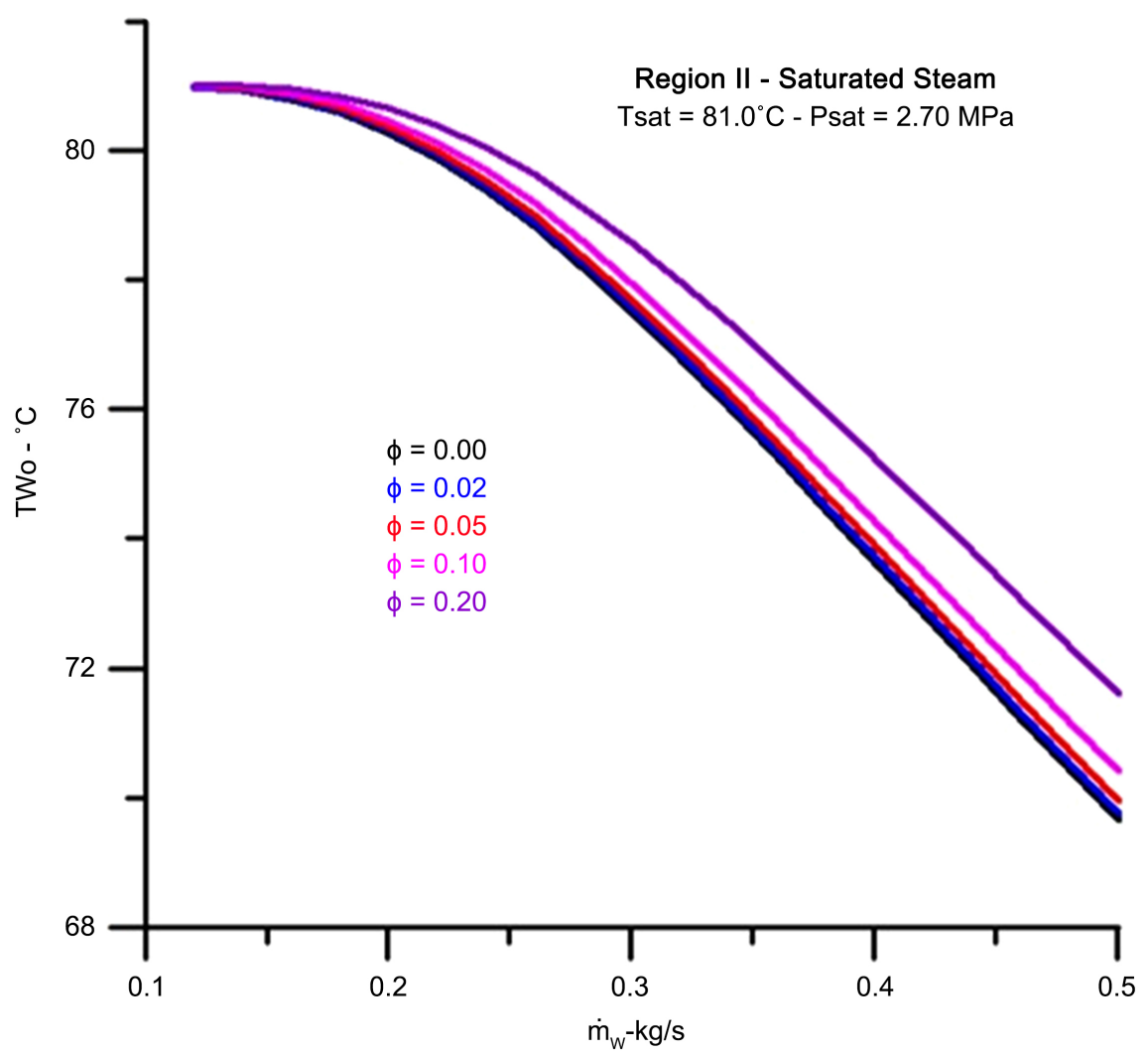

Figure 14. Nanofluid outlet temperature versus mass flow rate $\left(T s a t=81.0^{\circ} \mathrm{C}\right)$.

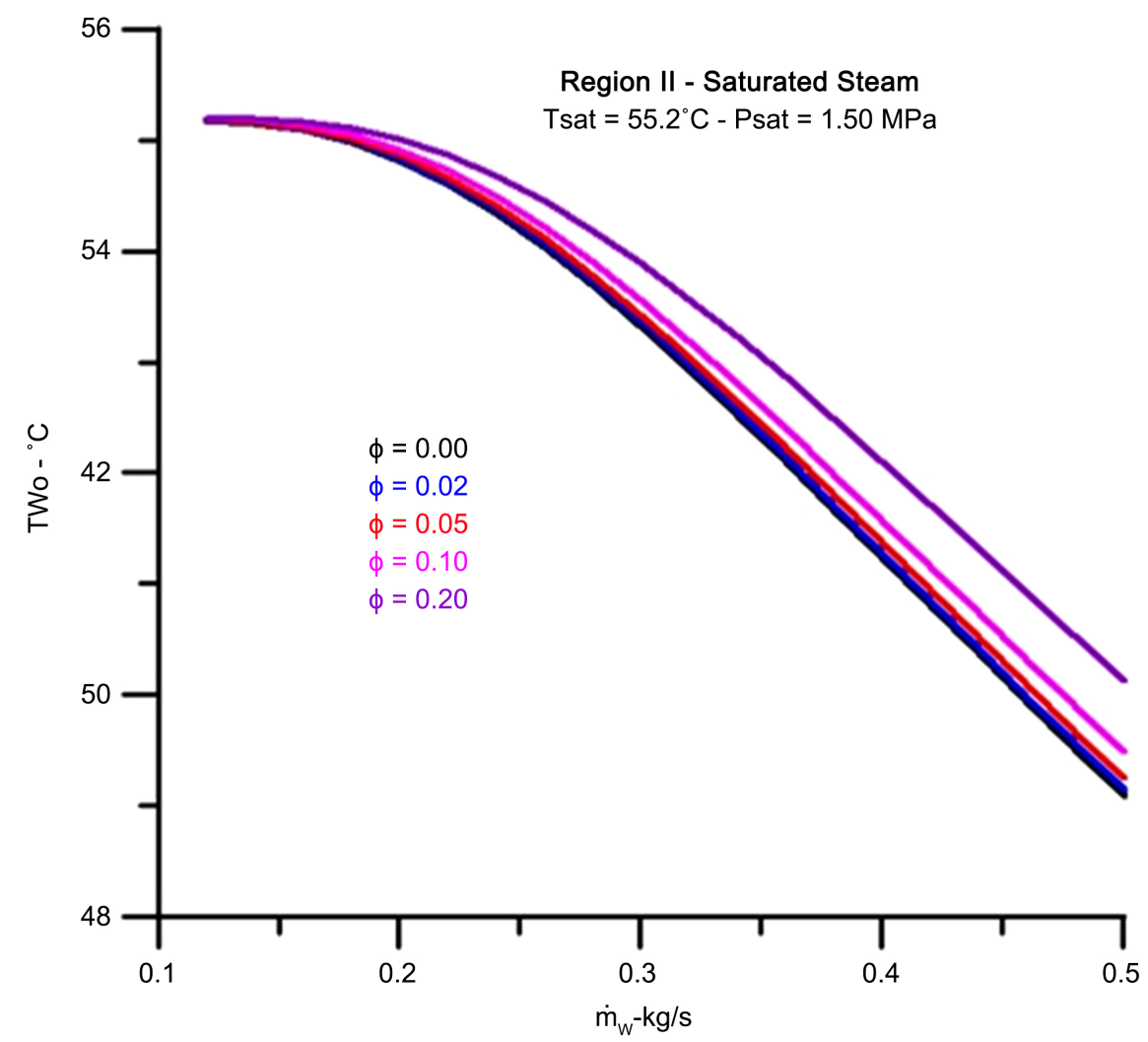

Figure 15. Nanofluid outlet temperature versus mass flow rate $\left(T s a t=55.2^{\circ} \mathrm{C}\right)$. 
- Effectiveness is high in all situations analyzed;

- The effectiveness is close to the maximum possible for high mass flow rates of the nanofluid, regardless of the volume fraction of the nanoparticles;

- Lower mass flow rates of the nanofluid enable higher outlet temperatures.

\subsection{Superheated Steam}

In this subsection, we present some results related to the superheated steam region. The fluid inlet temperature in the tubes is equal to the saturated steam region's outlet temperature, and the refrigerant inlet temperature is equal to $100^{\circ} \mathrm{C}$. The original number of the pass in the tube is equal to 3 . New numbers of the pass in the tube have been added for analysis of efficiency and effectiveness. The results obtained include global heat transfer coefficient, efficiency, effectiveness, and the nanofluid outlet temperature. The volume fraction of nanoparticles ranges from 0 to 0.20 , and the number of passes through the tube varies from 3 to 12 .

The variation of the global convective coefficient of heat transfer as a function of the aluminum oxide nanoparticles $\left(\mathrm{Al}_{2} \mathrm{O}_{3}\right)$, for the number of passes in the tube equal to 3 , is represented by Figure 16 . The global heat transfer coefficient increases $21.3 \%$ at the low nanofluid flow rate when the volume fraction equals 0.20 . However, for high flows, the relative increase is close to $6.1 \%$.

When the heat exchange area increases, by varying the number of passing in the tube from 3 to 12, the overall convective heat exchange coefficient decreases, as shown in Figure 17. This decrease occurs because the number of thermal units (NTU) remains the same: the amount of energy available is the same in this sub-region and depends on the refrigerant inlet and outlet temperatures, that is, Tsat and $100^{\circ} \mathrm{C}$, respectively.

The effectiveness is extremely low when considering the standard structure of the heat exchanger, when the number of steps in the tube is equal to three, as shown in Figure 18. This low effectiveness occurs even when the volume fraction of the nanoparticles ranges from 0.0 to 0.20 . However, the efficiency is too high.

When the number of the pass increases, from 3 to 12, as shown in Figure 19, the efficiency decreases but remains high. However, the effectiveness rises from 0.34 to 0.66 for a fraction in a volume equal to 0.10 .

Figure 20 and Figure 21 show the temperature profiles for nanofluid and refrigerant, for two different saturation temperatures, that is, $81.0^{\circ} \mathrm{C}$ and $64.7^{\circ} \mathrm{C}$. In both situations, the nanofluid outlet temperature is close to the refrigerant's inlet temperature for low flow rates of nanofluid.

Figure 22 shows the nanofluid outlet temperature for the number of passes in the tube ranging from 3 to 12 , with a fraction of nanoparticles equal to 0.10 . The outlet temperatures are higher for lower mass flow rates and increase with the pass in the pipe. However, the difference between temperatures is more significant for higher mass flow rates of nanofluid. These results are, of course, in line with the observable results for effectiveness, as shown in Figure 19. 


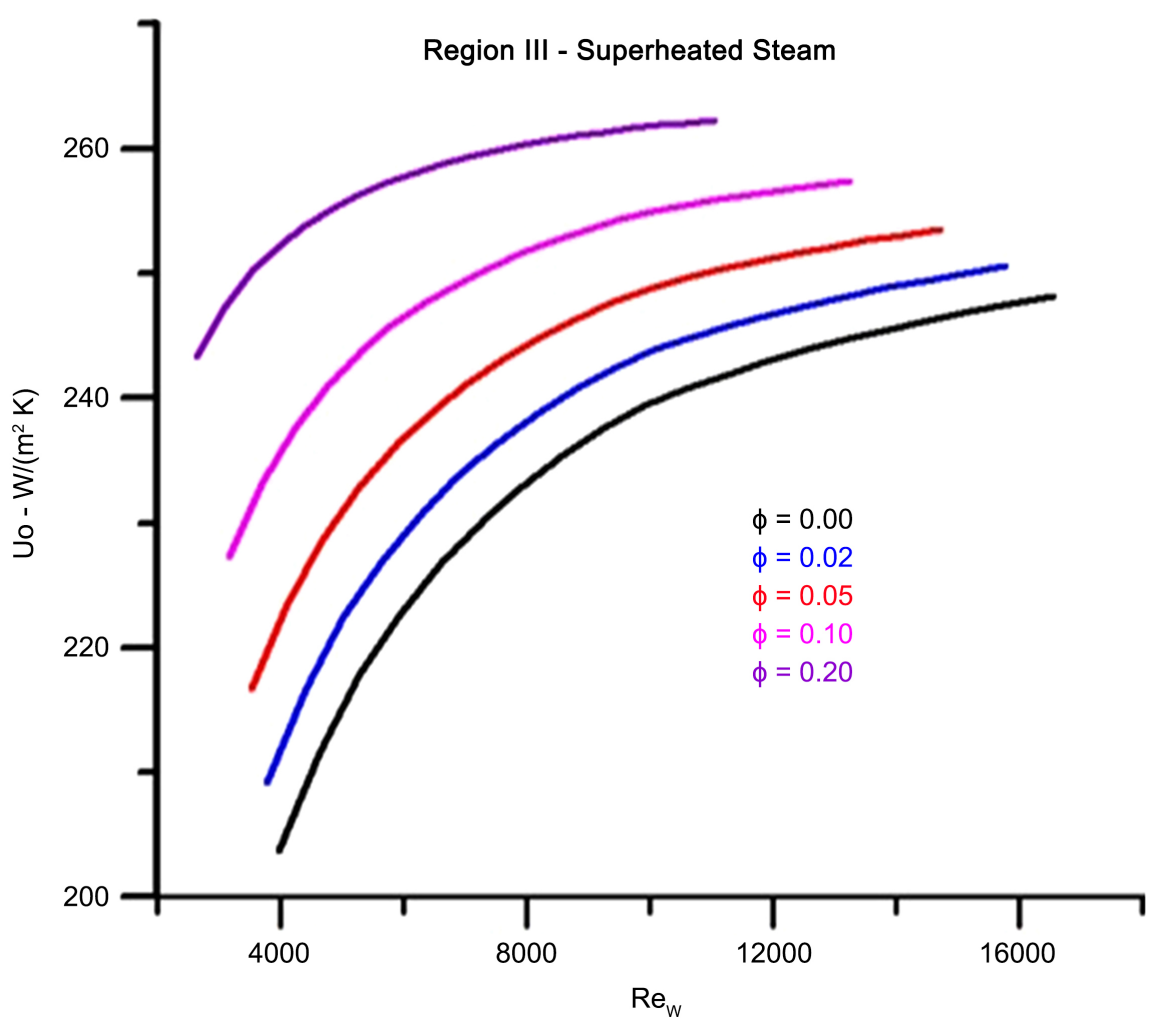

Figure 16. Global convective heat transfer coefficient versus Reynolds number of the nanofluid with a fraction of nanoparticles as a parameter (Npass $=3$ ).

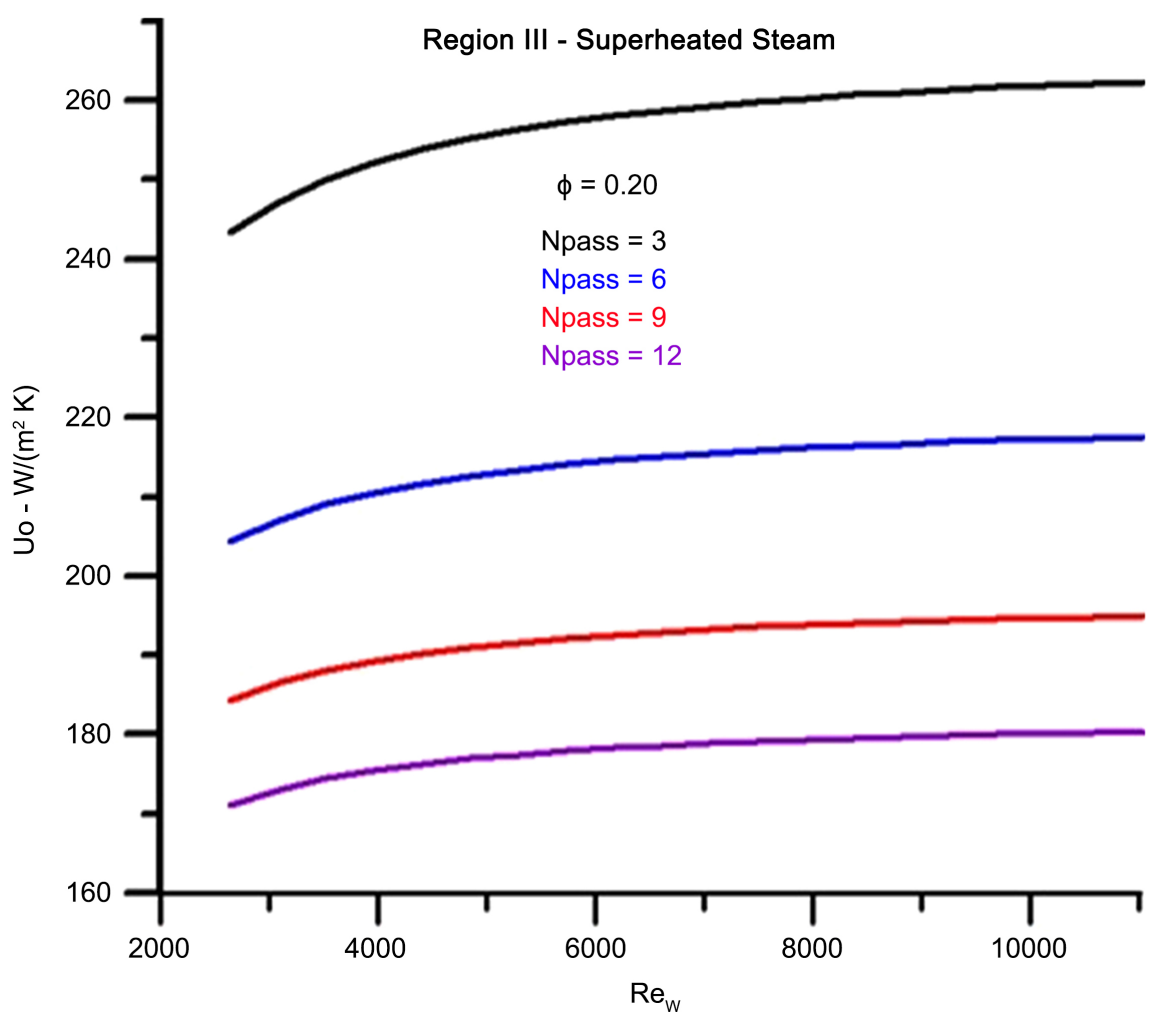

Figure 17. Global convective heat transfer coefficient versus Reynolds number of the nanofluid with pass number as a parameter. 


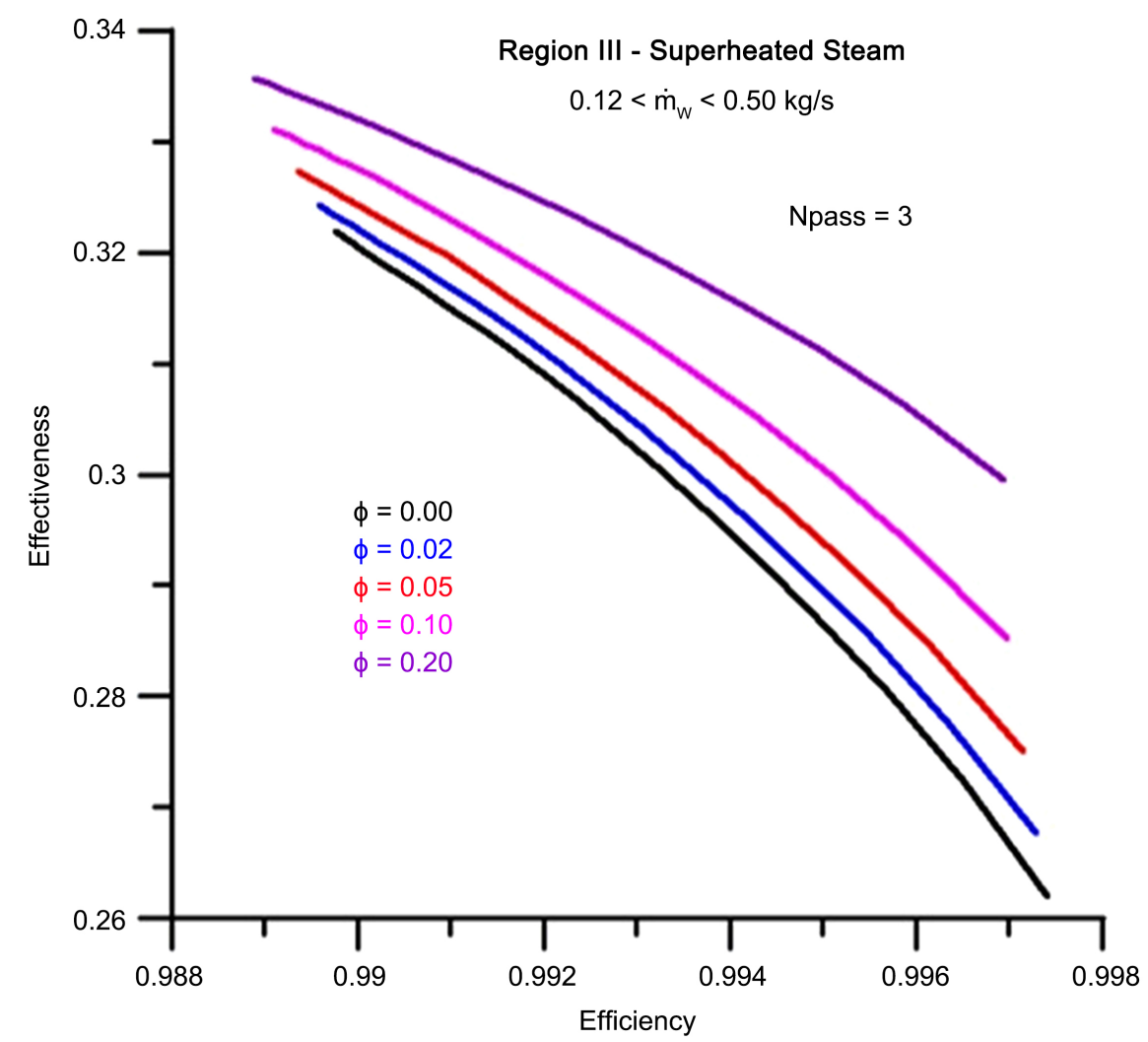

Figure 18. Effectiveness versus efficiency with a fraction of nanoparticles as a parameter.

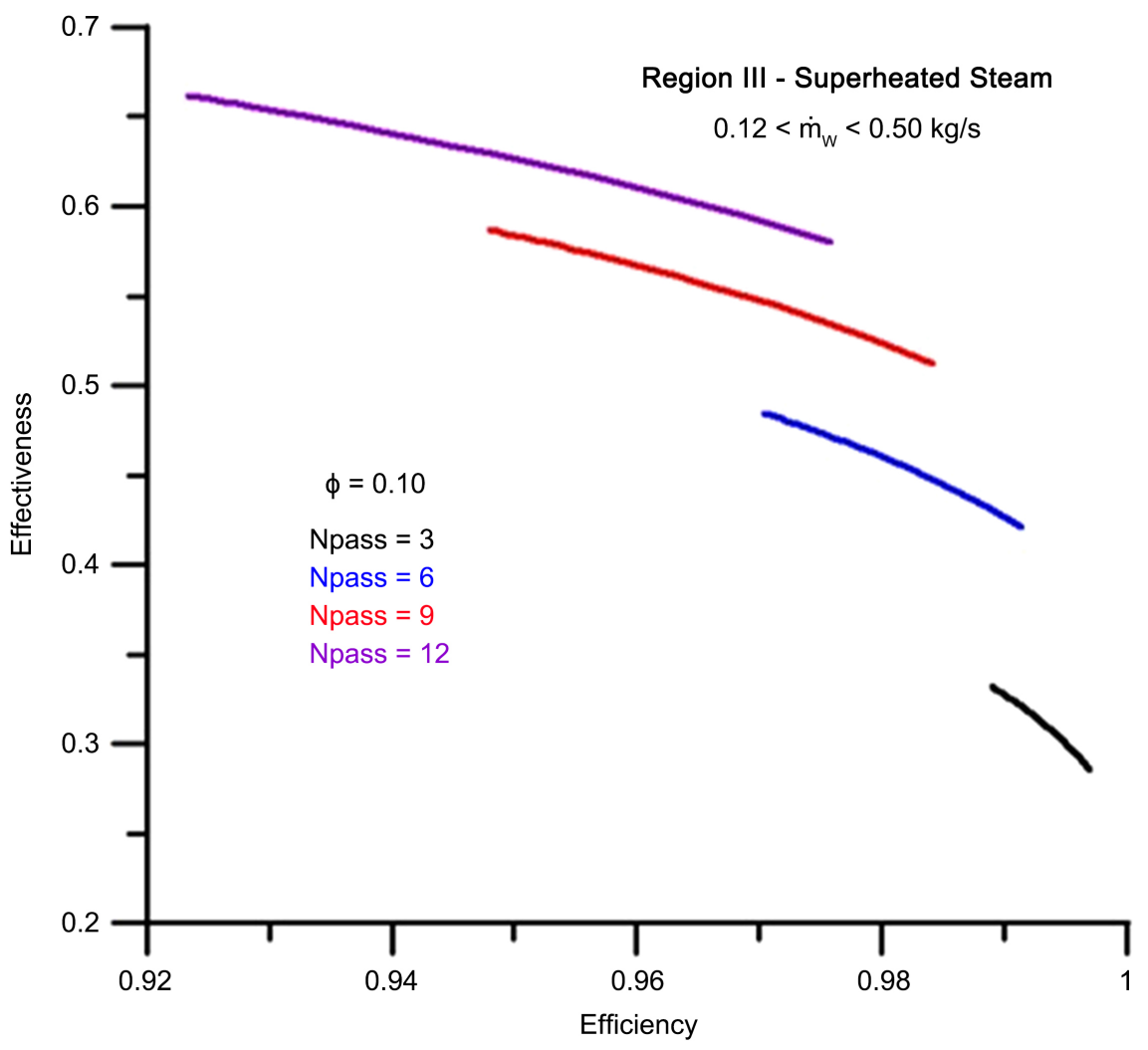

Figure 19. Effectiveness versus efficiency with fraction pass number as a parameter. 


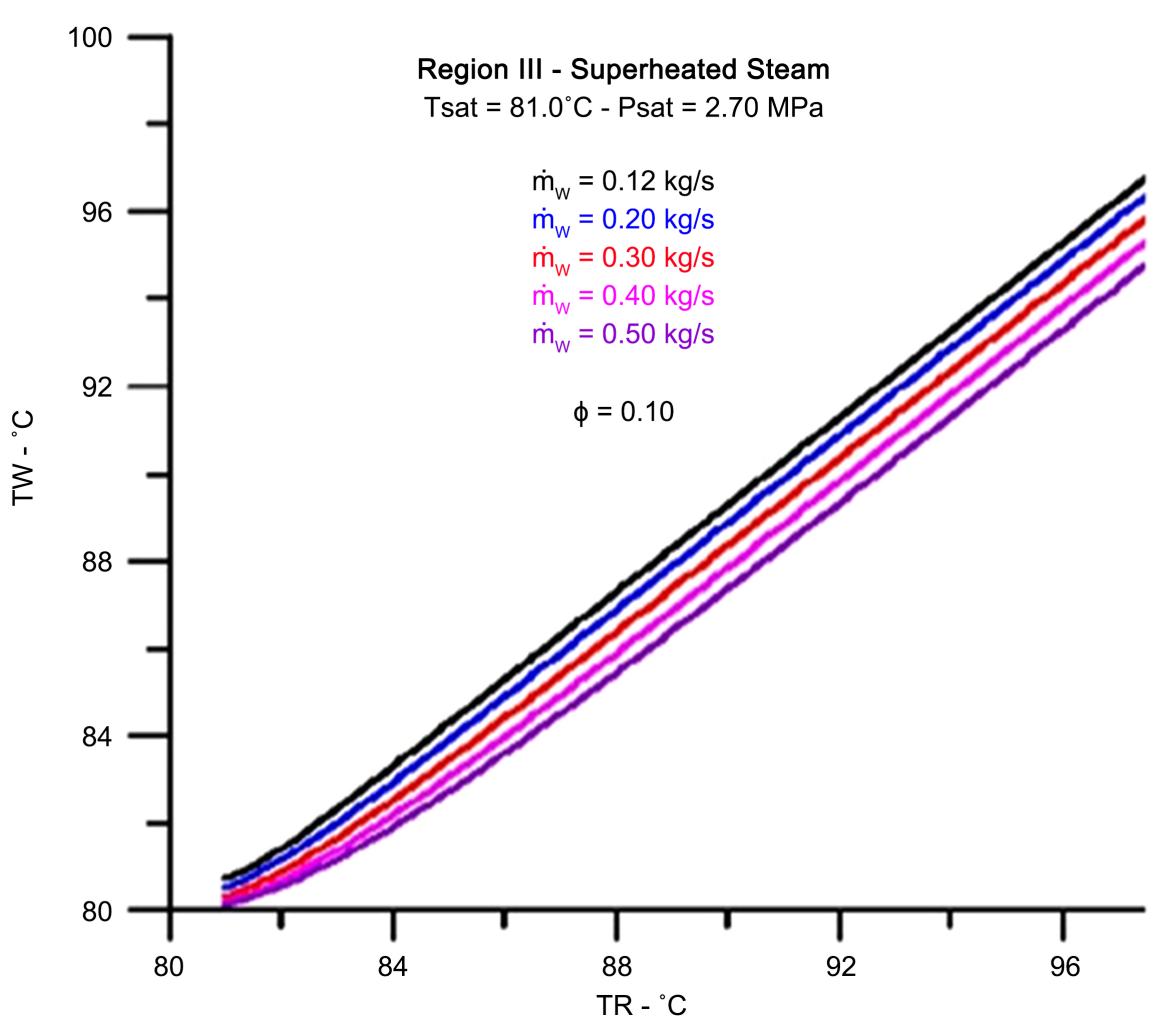

Figure 20. Nanofluid and refrigerant temperature profiles with mass flow rate as a parameter $\left(\right.$ Tsat $\left.=81.0^{\circ} \mathrm{C}\right)$.

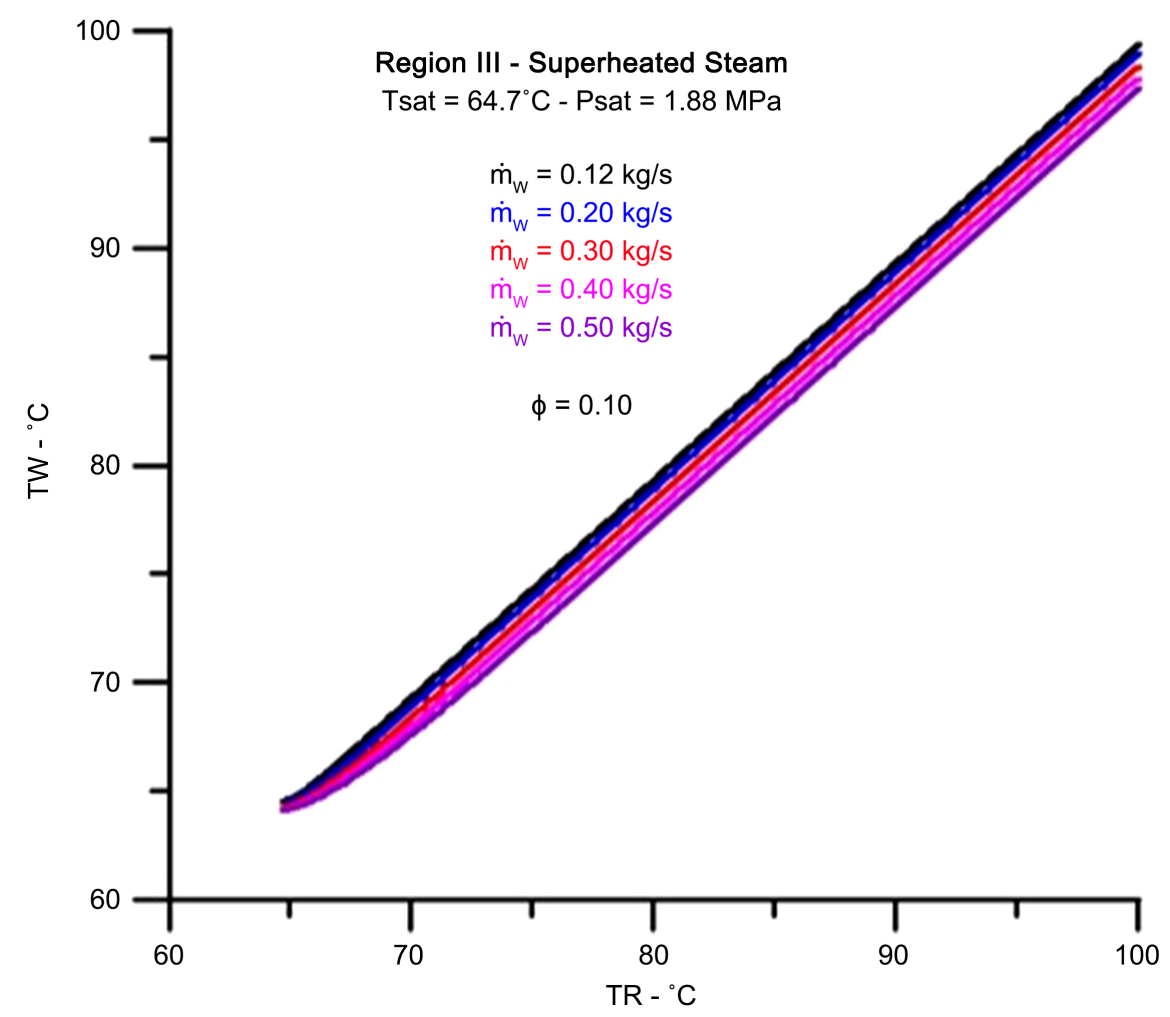

Figure 21. Nanofluid and refrigerant temperature profiles with mass flow rate as a parameter $\left(\right.$ Tsat $\left.=64.7^{\circ} \mathrm{C}\right)$. 


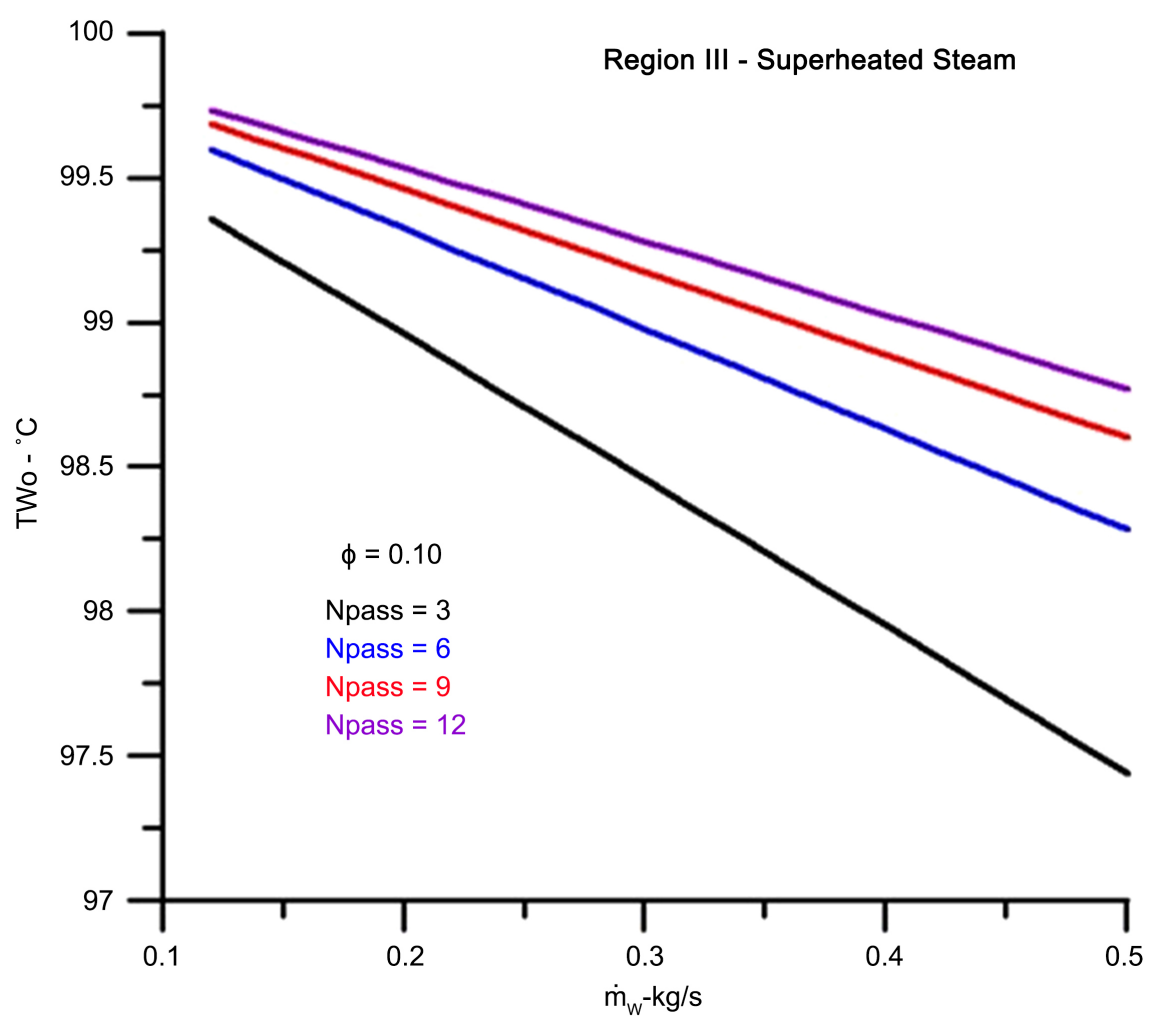

Figure 22. Nanofluid outlet temperature versus mass flow rate with the number of the pass in the tube as a parameter.

In summary, in the superheated steam region, there are:

- When the heat exchange area increases, by varying the number of passing in the tube from 3 to 12, the overall convective heat exchange coefficient decreases;

- The effectiveness is extremely low when considering the standard structure of the heat exchanger. However, the efficiency is too high;

- The effectiveness rises 0.34 to 0.66 when the number of the pass increases, for a fraction volume equal to 0.10 ;

- The nanofluid outlet temperature is close to the inlet temperature of the refrigerant for low flow rates of nanofluid and increases with the pipe's pass.

\section{Conclusions}

The work's main conclusions have already been described in the summaries for the heat exchanger's three regions. However, there are two more relevant situations to be answered based on the results obtained:

1) What is the most suitable configuration for the heat exchanger in question when the lowest outlet temperature for the refrigerant is desired?

2) What is the most suitable configuration for the heat exchanger in question when the nanofluid's highest outlet temperature is desired?

The answers drawn from the results described above for these two relevant questions are described below. 
The best configuration to obtain the lowest possible outlet temperature for the refrigerant is when there is a low fraction of nanofluid in the subcooled liquid region, a more significant number of steps in the tube, and a higher flow rate nanofluid, with a lower saturation temperature possible. The physical conditions of the two other regions of the heat exchanger may remain unchanged.

The best configuration to obtain the highest possible outlet temperature for the nanofluid is when one has the most considerable possible fraction of nanofluid, a more significant number of the pass in the tube, and a lower flow rate nanofluid the highest possible saturation temperature. The physical conditions of the two other regions of the heat exchanger may remain unchanged.

In the case under analysis, the effectiveness is only high in the two central regions of interest when the number of the pass in the tube is high. The number of passes is then the main parameter to obtain higher thermal performance about the standard configuration for a given saturation temperature.

\section{Conflicts of Interest}

The author declares no conflicts of interest regarding the publication of this paper.

\section{References}

[1] Nogueira, E. (2020) Theoretical Analysis of a Shell and Tubes Condenser with R134a Working Refrigerant and Water-Based Oxide of Aluminum Nanofluid $\left(\mathrm{Al}_{2} \mathrm{O}_{3}\right)$. Journal of Materials Science and Chemical Engineering, 8, 1-22. https://doi.org/10.4236/msce.2020.811001

[2] Nogueira, E. (2020) Thermal Performance in Heat Exchangers by the Irreversibility, Effectiveness, and Efficiency Concepts Using Nanofluids. Journal of Engineering Sciences, 7, 1-7. https://doi.org/10.21272/jes.2020.7(2).f1

[3] Lee, T.-S. and Mai, J.-W. (2011) Modeling and Simulation of the Heat Transfer Behavior of a Shell-and-Tube Condenser for a Moderately High-Temperature Heat Pump. In: Ahsan, A., Ed., Two-Phase Flow, Phase Change and Numerical Modeling, InTech, London, 61-82. https://doi.org/10.5772/19596

[4] Bejan, A. (1987) The Thermodynamic Design of Heat and Mass Transfer Processes and Devices. International Journal of Heat and Fluid Flow, 8, 258-276. https://doi.org/10.1016/0142-727X(87)90062-2

[5] Fakheri, A. (2007) Heat Exchanger Efficiency. Transactions of the ASME, 129, 1268-1276. https://doi.org/10.1115/1.2739620

[6] Almurtaji, S., Ali, N., Teixeira, J.A. and Addali, A. (2020) On the Role of Nanofluids in Thermal-Hydraulic Performance of Heat Exchangers-A Review. Nanomaterials, 10, 734. https://doi.org/10.3390/nano10040734

[7] Thakur, G. and Singh, G. (2017) An Experimental Investigation of Heat Transfer Characteristics of Water-Based $\left(\mathrm{Al}_{2} \mathrm{O}_{3}\right)$ Nanofluid Operated Shell and Tube Heat Exchanger with Air Bubble Injection Technique. International Journal of Engineering \& Technology, 6, 83-90. https://doi.org/10.14419/ijet.v6i4.7881

[8] Sun, Y., Wang, X., Long, R., Yuan, F. and Yang, K. (2019) Numerical Investigation and Optimization on Shell Side Performance of a Shell and Tube Heat Exchanger with Inclined Trefoil-Hole Baffles. Energies, 12, 4138. 
https://doi.org/10.3390/en12214138

[9] Mostafa, A.A.H., Khalil, E.E., El-Hariry, G., et al. (2017) Shell and Tube Heat Exchanger Performance. AIAA Propulsion and Energy Forum, 15th International Energy Conversion Engineering Conference, Atlanta, GA, 10-12 July 2017.

[10] Roy, R. and Mandal, B.K. (2014) Computer-Based Thermodynamic Properties of Alternative Refrigerant R-134a. Engineering Sciences International Research Journal, 2, 163-169.

[11] Vajjha, R.S. and Das, D.K. (2012) A Review and Analysis on Influence of Temperature and Concentration of Nanofluids on Thermophysical Properties, Heat Transfer and Pumping Power. International Journal of Heat and Mass Transfer, 55, 4063-4078. https://doi.org/10.1016/j.ijheatmasstransfer.2012.03.048 